Illinois State University

ISU ReD: Research and eData

Theses and Dissertations

$4-2-2021$

\title{
"It Was Too Many People To Like:" How Romantic Relationship Partners Of Bisexual Or Pansexual Individuals Express Jealousy
}

Emily Jae Mason

Illinois State University, emily.mj.mason@gmail.com

Follow this and additional works at: https://ir.library.illinoisstate.edu/etd

Part of the Communication Commons

\section{Recommended Citation}

Mason, Emily Jae, "'It Was Too Many People To Like:" How Romantic Relationship Partners Of Bisexual Or Pansexual Individuals Express Jealousy" (2021). Theses and Dissertations. 1389.

https://ir.library.illinoisstate.edu/etd/1389

This Thesis is brought to you for free and open access by ISU ReD: Research and eData. It has been accepted for inclusion in Theses and Dissertations by an authorized administrator of ISU ReD: Research and eData. For more information, please contact ISUReD@ilstu.edu. 


\section{“IT WAS TOO MANY PEOPLE TO LIKE:” HOW ROMANTIC PARTNERS OF BISEXUAL OR PANSEXUAL INDIVIDUALS EXPRESS JEALOUSY}

\section{EMILY JAE MASON}

\section{Pages}

Jealousy expression has been the topic of academic research for several years. As reflected by their Communication Responses to Jealousy Scale, Guerrero et al. (2011) determined 11 communicative responses to jealousy that fell into four distinct categories. However, the study of jealousy expression has yet to be applied to several underrepresented identities. Utilizing queer theory, this study aimed to explore which communicative responses to jealousy bisexual and pansexual individuals report receiving in dyadic romantic relationships with a monosexist partner and whether they perceived these responses to be related to their gender identity or sexual orientation. An online questionnaire was completed by 62 bisexual or pansexual participants who had been in a dyadic romantic relationship with a monosexist partner who had displayed jealousy expression. Through qualitative analysis, it was determined that participants experienced responses to jealousy that fit into all of Guerrero's four communicative responses to jealousy categories, some to a higher degree than others. Additionally, themes connecting gender and jealousy emerged, demonstrating the benefit of queering the study of jealousy expression. Implications of the study, limitations, and future research are then discussed.

KEYWORDS: Jealousy Expression, Gender Identity, LGBTQIA+, Bisexual, Pansexual 


\title{
“IT WAS TOO MANY PEOPLE TO LIKE:” HOW ROMANTIC PARTNERS OF BISEXUAL OR PANSEXUAL INDIVIDUALS EXPRESS JEALOUSY
}

\author{
EMILY JAE MASON
}

\author{
A Thesis Submitted in Partial \\ Fulfillment of the Requirements \\ for the Degree of \\ MASTER OF SCIENCE \\ School of Communication \\ ILLINOIS STATE UNIVERSITY
}


(C) 2021 Emily Jae Mason 
“IT WAS TOO MANY PEOPLE TO LIKE:” HOW ROMANTIC PARTNERS OF BISEXUAL OR PANSEXUAL INDIVIDUALS EXPRESS JEALOUSY

EMILY JAE MASON

COMMITTEE MEMBERS:

Aimee Miller-Ott, Chair

Lindsey Thomas

John Baldwin 


\section{ACKNOWLEDGMENTS}

First and foremost, I could not have achieved this without the support of my family. To my sisters, thank you for the laughter, the coffee runs, and your wonderful support throughout all my academic highs and lows. To my dad, thank you for teaching me the benefit of "sucking it up and walking it off." Finally, to my mom, thank you for being an endless source of support and inspiration. Thank you for your strength and thank you for every late-night tear-filled phone call. There is no doubt in my mind that who I am and what I have done is a direct result of your uncompromising belief in me.

Additionally, I would be remiss if I did not thank my phenomenal committee. Dr. Baldwin, thank you for your kindness, expertise, and brilliantly executed humor. It was your class that gave me the push to tackle a qualitative method. Dr. Thomas, thank you for inspiring me to relentlessly better myself as person and academic. You will never quite know how much being in your Family Comm. class changed me as an aspiring life-learner. Finally, Dr. Miller-

Ott, there is no way I could have accomplished this without your incredibly enduring support and patience. I began this thesis knowing it would be a bumpy road, but your thoughtful encouragement always gave me the confidence to "go, go, go."

From a young age I knew that my pursuit of academic success would not be easy. Against many odds, I am ecstatic to be completing my thesis, and with it, an M.S. in Communication. Although I will never be able to thank everyone, I am endlessly grateful for every teacher, therapist, mentor, friend, and family member who has supported me along the way.

E. J. M. 


\section{CONTENTS}

Page

ACKNOWLEDGEMENTS

$\begin{array}{ll}\text { CONTENTS } & \text { ii }\end{array}$

CHAPTER I: INTRODUCTION 1

CHAPTER II: REVIEW OF LITERATURE

Jealousy $\quad 4$

Experience and Expression of Romantic Jealousy 5

Experience of Jealousy $\quad 6$

Experience of Jealousy and Gender/Sexuality 6

$\begin{array}{ll}\text { Expression of Jealousy } & 8\end{array}$

Interactive Communicative Responses. 8

General Behavioral Responses. $\quad 9$

Evolution of CRJ Scale. $\quad 10$

LGBTQIA+ Identity in Communication $\quad 12$

$\begin{array}{ll}\text { Queer Theory } & 13\end{array}$

Bisexuality/ Pansexuality and Jealousy Expression 15

$\begin{array}{ll}\text { CHAPTER III: METHODS } & 19\end{array}$

Recruitment/ Participants 19

$\begin{array}{ll}\text { Procedures } & 19\end{array}$

$\begin{array}{ll}\text { Data Collection Protocol } & 20\end{array}$

$\begin{array}{ll}\text { Data Analysis } & 22\end{array}$

CHAPTER IV: RESULTS 24 
Communicative Responses to Jealousy

$\begin{array}{ll}\text { Constructive Communication } & 24\end{array}$

Destructive Communication $\quad 25$

$\begin{array}{ll}\text { Negative Communication } & 25\end{array}$

$\begin{array}{ll}\text { Violent Communication } & 26\end{array}$

Violent Threats. $\quad 26$

$\begin{array}{ll}\text { Violent Actions. } & 27\end{array}$

$\begin{array}{ll}\text { Counter-Jealousy Induction } & 27\end{array}$

Avoidant Communication 28

$\begin{array}{ll}\text { Silence } & 28\end{array}$

Rival-Focused Communication $\quad 30$

$\begin{array}{ll}\text { Surveillance } & 30\end{array}$

$\begin{array}{ll}\text { Rival Contact } & 31\end{array}$

Signs of Possession 31

$\begin{array}{ll}\text { Rival Derogation } & 32\end{array}$

Perceived Impact of Sexual Orientation on Jealousy Expression 33

Monosexist Misinformation $\quad 34$

Attracted to Everyone 34

Misunderstanding the LGBTQIA+ Community 35

Decreased Trustworthiness 36

$\begin{array}{ll}\text { Gender Identity and Perceived Threat } & 37\end{array}$

$\begin{array}{ll}\text { Partners Who Were Men } & 38\end{array}$

Men as the Threat 38 
Partners Who Were Women

Men as the Threat

CHAPTER V: DISCUSSION 46

Summary of Findings $\quad 46$

Research Conclusion and Implications of the Study $\quad 50$

Queering the Study of Jealousy Expression 50

Gender Identity Impact $\quad 54$

Absence of Constructive Communication of Jealousy 56

$\begin{array}{ll}\text { Practical Implications } & 57\end{array}$

$\begin{array}{ll}\text { Increasing Partner Awareness } & 58\end{array}$

$\begin{array}{ll}\text { LGBTQIA+ Safety } & 59\end{array}$

Addressing Stigma in the LGBTQIA+ Community 60

$\begin{array}{ll}\text { Limitations and Future Directions } & 61\end{array}$

$\begin{array}{ll}\text { Participant Demographics } & 61\end{array}$

Data Collection Structure $\quad 62$

$\begin{array}{ll}\text { Conclusion } & 63\end{array}$

$\begin{array}{ll}\text { REFERENCES } & 64\end{array}$

APPENDIX A: RESEARCH BOARD RECRUITMENT 72

APPENDIX B: EMAIL RECRUITMENT $\quad 73$

APPENDIX C: SOCIAL MEDIA RECRUITMENT POST 74 


\section{CHAPTER I: INTRODUCTION}

More than $90 \%$ of dating partners report experiencing jealousy to some degree (KennedyLightsey \& Booth-Butterfield, 2011). Not only is jealousy a commonly experienced emotion, but it is also arguably one of the more common themes in modern media. What drove Ross and Rachel apart in Friends? It was Ross's jealousy of Mark. Why in New Girl, is Jessica Day unkind towards her boyfriend's old medical school friend? Undeniably, she is jealous of their shared history and chemistry. Why did Ron sabotage Hermione's date at the Yule Ball in Harry Potter? Arguably, his behaviors stemmed from none other than the little green-eyed monster itself - jealousy. As these media examples illustrate, romantic jealousy, conceptualized as an interpersonal experience that consists of cognitive, emotional, and behavioral components and includes a protective reaction to threats posed by third-party rivals (Bevan, 2013), is ever present in people's close interpersonal relationships.

It is critical to consider the last part of the previously mentioned definition (i.e., thirdparty rivals). What constitutes a threatening third-party rival? Some scholars argue that, from an evolutionary perspective, the perception of a rival is triggered by a threat to an instinctual reproductive need, and therefore is heavily dependent on gender identity (Buss, 2018; Sagarin et al., 2012; Sheets \& Wolfe, 2001). For males, when one perceives a romantic threat, there is a chance of one's paternity being jeopardized (Buss, 2018). For females, when there is a romantic threat, one can anticipate a potential alteration in time, commitment, parental investment, and resources (Buss, 2018). However, if this is the case, why does one's romantic partner feel threatened by an individual with whom their partner could not reproduce? How is a romantic partner's expression of romantic jealousy different when the "third-party rival" is not a threat rooted in the possibility of reproduction? 
These questions are the foundation of, and inspiration for, the present study. Many people experience this very human emotion of romantic jealousy (Kennedy-Lightsey \& BoothButterfield, 2011however, certain identities have not been included in this research. Specifically, there has been very little research conducted looking at romantic jealousy in the LGBTQIA+ community (Carpenter, 2012; Scherer et al., 2013). Communication scholars are uniquely positioned to study the ways in which sexual diversity intersects with communication processes "given the field's central concern with human symbolic behavior in social, cultural, and historical context(s)" (Henderson, 2001, p. 468). In the present study, the researcher's central focus was to better understand the lived experiences of LGBTQIA+ members in relation to perceived romantic jealousy expression.

Specifically, the researcher chose to focus on the lived experiences of individuals who identify as bisexual or pansexual. Bisexuality is operationally defined as when an individual is attracted to both men and women (Scherer et al., 2013). Pansexuality is defined as an individual whose romantic attraction is not dependent on gender, meaning that they identify as an individual who is sexually, emotionally, romantically, or spiritually attracted to others, regardless of biological sex, gender expression (of masculine or feminine characteristics), or sexual orientation (Rice, 2015). As previously explained, there is a notable lack of consideration for LBGTQIA+ identities in academic research. However, there is also a misrepresentation in the media of the lived experiences/identities of bisexual and pansexual individuals (Madison, 2017). In the previously provided media examples, there appeared to be no reason for the characters to experience jealousy. However, when we examine examples of jealousy motivation in the media in relationships of bisexual and pansexual individuals, jealousy is often rooted in cheating and/or a lack of loyalty. The trope of the dishonest pansexual or bisexual partner is so present that even 
pop-culture personnel comment on its prevalence. For example, in a 2016 Revelist article, McNally observed that, in the media, many bisexual characters "fall victim to stereotypes and are often depicted as evil, manipulative, non-monogamous, and hypersexual" (para.1). Whether it is Piper Chapman in Orange is the New Black or Bonnie Winterbottom in How to Get Away with Murder, it appears that American media often paint bisexual and pansexual individuals as untrustworthy cheaters, and thus a study of jealousy in their romantic relationships is important.

In short, the researcher wants to provide the perspective of bisexual and pansexual individuals in research on romantic jealousy expression. As self-reported self-perception can be influenced by one's susceptibility to self-presentation bias (Barta \& Kiene, 2005), the researcher aimed to have a less bias-driven perception of the romantic jealousy expression. If this study's collected responses were from the partners' perspective, there is a potential for self-presentation bias and/or fundamental attribution error to illicit inaccurate reflective responses. Henceforth, the researcher chose to collect data from bisexual and pansexual participants who perceived that they were the recipients of jealousy expression from their partners. Utilizing queer theory and an adaptation of the Communicative Responses to Jealousy (CRJ) scale, the researcher developed this study to explore bisexual and pansexual individuals' perceptions and sense-making of how and why their past partners expressed romantic jealousy to them. 


\section{CHAPTER II: REVIEW OF LITERATURE}

The present study sought to explore romantic jealousy expression among people with under-addressed identities, that of bisexuality and pansexuality. First, it is important to understand the research that previously exists outlining the factors contributing to this study. The following literature review will outline previous research conducted on romantic jealousy expression, the present place of the bisexual and pansexual community in academic research, and the minimal information available about the intersectionality between romantic jealousy expression and sexuality.

\section{Jealousy}

Jealousy is an interpersonal experience that consists of cognitive, emotional, and behavioral components and includes a protective reaction to threats posed by third party rivals (Bevan, 2013). Romantic jealousy is a complex construction of thoughts, feelings, and behaviors that arise when the quality or existence of a person's romantic relationship is threatened by a real or imagined rival (Guerrero \& Andersen, 1998; White \& Mullen, 1989).

In part, due to jealousy complexity, romantic jealousy has both a bright side and a dark side (Guerrero, 2014). First, studies show that romantic jealousy can reinforce commitment, increase attraction, and renew one's sense of appreciation for a partner (Buss, 2018; Pines, 1992). Additionally, romantic jealousy can be used as a tool to signal that people need to pay more attention to their partner and their relationship (Buss, 1988; Pines, 1992). Sometimes romantic jealousy can lead couples to renegotiate relational rules and reaffirm their commitment, which may ultimately strengthen relationships (Buss, 2018; Pines, 1992). As Bevan (2013) noted, constructive responses to romantic jealousy are the primary form of jealousy communication that has been found sometimes to associate positively with relational satisfaction. 
However, jealousy is sometimes associated with negative relational outcomes, such as dissatisfaction, conflict, uncertainty, and possessiveness (Carson \& Cupach, 2000; Fleischmann et al., 2005; Guerrero \& Andersen, 1998). According to a Federal Bureau of Investigation (FBI) (2013) report detailing US crime rates between 2009 and 2013, a total of 433 homicides were committed because of a "romantic triangle," wherein jealousy likely played a role. Romantic jealousy has been linked to violent crime, depression, and suicidal thoughts (Buss, 2018; Carson

\& Johnson, 1985; Mathes et al., 1985). Additionally, romantic jealousy has been associated with uncertainty (Bevan, 2004). Uncertainty may be heightened in cases of perceived threat to a relationship, and when partners have more uncertainty, they also report lower relationship satisfaction (Dainton, 2003). Thus, jealousy can negatively impact one's perceived relational satisfaction.

Scholars have conducted research for years on the benefits and obstacles of experiencing and expressing romantic jealousy (Guerrero, 2014). Studies indicate that romantic couples who communicate their jealousy in constructive ways are less likely to experience dark-sided negative outcomes and are more likely to report being satisfied with their relationships despite the experience of jealousy (Andersen et al., 1995; Guerrero \& Andersen, 1998). This potential impact on relational satisfaction warrants the need to further understand both the experience and expression of romantic jealousy.

\section{Experience and Expression of Romantic Jealousy}

People experience romantic jealousy internally through thoughts and emotions but also express romantic jealousy externally through various behaviors (Dainton \& Aylor, 2001; Fleischmann et al., 2005), making romantic jealousy not only a cognitive and psychological experience but also a communicative one. There is a distinction between the experience and 
expression of jealousy (Guerrero, 1998). Jealousy is rarely experienced as a solely intrapersonal phenomenon and can be comprised of actions that occur in private, spontaneous expressions of jealous emotion, and strategic communication that is directed at others (Guerrero, 1998). This is decidedly different from the experience of jealousy, which is felt and not necessarily perceivable by others.

\section{Experience of Jealousy}

There are three types of experienced romantic jealousy: reactive, anxious, and preventive (Buunk, 1997). Reactive jealousy occurs when a partner is responding to a direct threat to the relationship such as emotional or sexual infidelity. Anxious jealousy occurs when an individual worries or ruminates about infidelity, but there is no concrete, direct threat to the relationship. For example, if a wife keeps coming home late from work, her husband may become jealous thinking that she is spending time with another man. In this case, there is no real, tangible rival threatening the relationship; the rival is in the mind of the husband. The third is preventive jealousy, which Barelds and Barelds-Dijkstra (2007) referred to as possessive jealousy. Possessive jealousy has a stronger behavioral aspect that includes preventing a romantic partner from contacting potential rivals (Buunk, 1997). Possessive jealousy involves a feeling of “ownership" and "territory" towards one's partner. For example, a man might put an arm around his girlfriend to show that she is "taken" if he notices other men looking at her. Barelds and Barelds-Dijkstra (2007) found that reactive jealousy typically occurs in high-quality relationships, whereas anxious jealousy occurs in low-quality relationships.

\section{Experience of Jealousy and Gender/Sexuality}

Several factors have been found to impact the experience of jealousy. Specifically, one's sexual orientation may influence one's experiences of jealousy (Sagarin et al., 2003). Notably, 
same-sex and opposite-sex romantic dyads do not significantly differ in level of cognitive or affective jealousy experience (Bevan \& Lannutti, 2002). However, when considering relationships that include an individual who is bisexual or pansexual, previous research has found that the sex of the individual involved in the infidelity scenario with the opposite-sex member of the relationship played a key role in the type of jealousy felt by a partner (Sagarin et al., 2003). Additionally, the double shot hypothesis (DSH) suggests that it is the gender of the unfaithful partner that determines the meaning and threat implied by infidelity —not the gender of the betrayed partner (Sheets \& Wolfe, 2001). The DSH states that for women, jealousy comes from the belief that emotional infidelity by their partner implies that their partner has committed sexual infidelity (DeSteno \& Salovey, 1996; Harris \& Christenfeld, 1996). This hypothesis also suggests that homosexual men should perceive and react to their partners' infidelity in the same way as heterosexual women, meaning that homosexual men and heterosexual women are more concerned about emotional aspects of the infidelity. Controversially, the DSH proposes that homosexual women should perceive their partners' infidelity in the same way as heterosexual men, meaning that they are more concerned about the sexual aspects of the infidelity.

However, a second controversial approach to studying jealousy is the reproduction threatbased mode (RTBM; Sagarin, et al., 2012). RTBM states that sex differences in jealousy have developed in response to a reproductive instinct. RTBM predicts that the sexes will differ only when the jealous perceivers' reproductive outcomes are differentially at risk. For example, men whose female partners are having a sexual relationship with other men would be more focused on the sexual aspects of the infidelity while men whose male partner is dating other man would focus on the emotional aspects of the infidelity, given that there is no risk of impregnation. 
The RBTM and the DSH have some overlap, most notably that they make similar predictions when it comes to how men dating women, men dating men, and women dating men experience jealousy. However, these two approaches to studying romantic partner jealousy have different predictions regarding women dating women. The DSH predicts that sexual infidelity will be as distressing as the emotional infidelity because sexual infidelity implies emotional infidelity. RTBM predicts that emotional infidelity will be more distressing because there is no reproductive threat in this scenario.

While these academic frameworks are helpful to understanding potential reasons for experiencing jealousy, past research does not address how the sexual orientations present in dyadic relationships influence a relationship partner's communicative response to jealousy (i.e., jealousy expression). Jealousy expression positions communication at the center of the psychological and relational experience of this emotion.

\section{Expression of Jealousy}

A communicative response to jealousy is " a behavioral reaction to jealousy that carries communicative value and has the potential to fulfill individual and/or relational goals"' such as reducing uncertainty, maintaining one's relationship, or bolstering one's self-esteem (Guerrero et al., 1995, p. 272). Guerrero and colleagues originally identified 11 communicative responses to jealousy. These 11 communicative responses were then crafted into the Communicative Responses to Jealousy (CRJ) Scale (Guerrero et al., 1995). Guerrero and colleagues first divided these 11 response into two categories: interactive communicative responses and general behavioral communicative responses.

Interactive Communicative Responses. Six of these 11 communicative responses to jealousy are labeled as interactive communicative responses (Guerrero et al., 1995). An 
interactive communicative response is one in which an individual consciously communicates (or avoids communicating with) their partner. To clarify, this is partner-directed communication (Guerrero et al., 1995). While communicative responses were originally described as those occurring during face-to-face interactions, many of the following interactive communication categories can now additionally occur via mediated communication. virtually. The interactive responses are negative affect expression, integrative communication, distributive communication, active distancing, avoidance/denial, and violent communication/threats.

Negative affect expression is a nonverbal display of jealous-related emotions (e.g., frustration, sadness, or anger). Integrative communication occurs when one attempts to problemsolve. This response type can also include an effort to disclose feelings and concerns. In contrast, distributive communication occurs when one engages in more aggressive communication (e.g., yelling at or acting rude toward the partner). While the previous expressions involve engagement of some sort, an avoidance/denial expression of jealousy is when one "shuts down" communication which includes denying jealous feelings. Active distancing can include indirect, yet aggressive behaviors. Examples include giving the partner cold or dirty looks or leaving the scene in anger. Active distancing is different than an avoidance/denial expression in the sense that when one avoids/denies a feeling of jealousy, their expression indicates that there is no problem, whereas active distancing indicates an acknowledgement of the issue but an unwillingness to engage in direct communication about it. Finally, violent communication expression is when a partner reaches the point of threatening to engage in physical violence as a response to their feelings.

General Behavioral Responses. There are also five general behavioral responses to jealousy (Guerrero et al., 1995). General behavioral responses to jealousy, while often aimed at 
the partner, do not always involve direct communication between the two partners (Guerrero, 1998). In other words, a non-direct communicative response means that there is no intent of explicit communication with one's partner through the expression of jealousy. The five nondirect communicative responses are: surveillance/restriction, compensatory restoration, manipulation attempts, rival contacts, and violent behavior.

Surveillance/restriction includes intentionally observing one's partner (e.g. spying, checking the partner's whereabouts, looking through the partner's possessions). For example, one could watch their partner on Snap-maps or try to find the password to get into a partner's phone. The compensatory restoration response involves attempts to make oneself appear to be a better partner, thus making the relationship more attractive. For example, the partner feeling jealous could send flowers or dress up. Manipulation attempts involve efforts to manipulate the partner's emotions. Often this can come in the form of counter-jealousy (i.e., trying to make one's partner more jealous than one is) and/or trying to make one's partner feel guilty for their actions. Rival contacts involve one communicating with, and often threatening or warning, the "rival" (i.e., the threat). Finally, violent behavior as a general behavioral response encompasses violence as an indirect expression of jealousy, masked as anger (e.g., slamming doors or throwing items). This is not the same as an interactive expression of romantic jealousy which, as stated, can involve direct threats of physical altercations.

Evolution of CRJ Scale. Guerrero and colleagues (2003) revised the Communicative Responses to Jealousy scale and added signs of possession, derogating competitors, and relationship threats as additional responses to jealousy, thus resulting in 14 total communicative responses. Signs of possession qualify as when one partner publicly displays the relationship to others, often in order to show that their partner is taken (e.g., putting their arm around their 
partner when around others). Rival Derogating occurs when a partner attempts to try to reduce the appeal of rivals by criticizing or making negative comments about them. Finally, relationship threats occur when a partner threatens to terminate or de-escalate the relationship or to be unfaithful.

Guerrero and colleagues (2011) later sorted these expressions of jealousy into four general strategy categories (i.e., constructive, destructive, avoidant, rival-focused) that include a total of 11 communicative responses to jealousy, which are the focuses of the present study. The constructive category includes integrative communication and compensatory restoration and is demonstrated by communicating direct and positive messages. Constructive communication is often used when the partner is demonstrating an effort to making the relationship better. The destructive category includes negative affect expression, violent communication/behavior, and manipulation attempts. Destructive communication is demonstrated by being openly or indirectly hurtful, distancing, or attempting to make one's partner jealous. For example, destructive communication could come in the form of violent threats or actions toward the partner or objects. Additionally, negative communication within the destructive category could be displayed as flirting or cheating with an individual who is not one's partner. The avoidant category includes being silent or making denials about the relationship and/or experience of jealousy. This category includes silence and avoidance/denial. Finally, the rival-focused category includes surveillance/restriction of partner's communication, contacting rivals, derogating rivals, and exhibiting signs of possession.

In summary, there are many ways that romantic jealousy expression may present itself. Communicative responses to jealousy are also associated with relationship characteristics like length of relationship, status of relationship, relationship satisfaction, and identities of the 
relationship participants (Guerrero et al., 2011). However, one such relationship factor that has been largely omitted from the study of jealousy expression is the impact of sexual orientations of partners within a dyadic romantic relationship. As previously noted, the existing research does indicate that romantic jealousy expression is different based on one's gender identity (Guerrero, 2014). However, this is often attributed to a perceived risk to reproduction (Sagarin et al., 2012). This means that, perhaps unknowingly, romantic jealousy expression has predominantly been researched through the lens of heterosexual experiences. However, scholars have found that different sexual orientations of romantic partners can impact romantic jealousy experience (Harris, 2002; Sagarin et al., 2003). Henceforth, this gap in literature begs the question: If the notion that jealousy experience can be impacted by sexuality and jealousy expression has predominantly been studied through the lens of heterosexual norms, could jealousy expression within relationships be related to the sexual orientations present in a dyadic romantic relationship? Therefore, the present study intended to consider additional sexual orientations when examining the expression of jealousy in romantic relationships by utilizing queer theory.

\section{LGBTQIA+ Identity in Communication}

\section{LGBTQIA+ stands for Lesbian, Gay, Bisexual/Pansexual, Transgender, Queer/}

Questioning, Intersex, Agender, Asexual, and Ally. The + is intended to include everyone in the gender and sexually expansive community, and this abbreviation is often casually referred to as the queer community. To specify, the term "queer" can be used as an adjective, a noun, or a verb. However, in conventional usage, it is most commonly an adjective, meaning "not normal," or, when referring to sexual orientation, not heterosexual (Dilley, 1999).

With over 9 million Americans identifying as LGBT as of 2011 (Gates, 2011), there is an undeniable presence of the queer community in the United States. Although scholars have 
studied queer communication, historically, these studies focused on members of the LGBTQIA+ community have been "hidden" in low-impact book chapters and journals (Manning et al., 2020). Manning et al. (2020) encourage emerging queer scholars to value the work previously conducted even if it was not given appropriate recognition in its time. By recognizing queer communication research, scholars can avoid queer erasure by avoiding incorrectly labeling one's own research as "novel," "new," and/or "groundbreaking" (p. 420). A large portion of this queersensitive and centered research includes the implementation of queer theory.

\section{Queer Theory}

Queer theory grew out of activist movements in the 1990s. Specifically, this theory originates from groups such as Queer Nation, who took activism to the streets to protest the lack of response to queer communities who were suffering from the emerging HIV/AIDS crisis (Manning et al., 2020). Queer theory, in short, is a transdisciplinary and postmodern theory that exists to question presumptions, values, and viewpoints from marginal and central positions (Dilley, 1999). As it has an understandably vague and evolving definition, some scholars view queer theory as intimidating and not practical (Manning et al., 2020). However, when utilized appropriately, queer theory has offered and continues to offer a lot to the study of communication.

Since its origin, queer theory has expanded past being a solely LGBTQIA+ theory. Scholars have utilized queer theorizing and thinking to challenge racist, sexist, ableist, and classist structures of knowledge (Eguchi \& Calafell, 2020). Queer theory, at its roots, is:

Less a matter of explaining the repression or expression of a homosexual minority than an analysis of the hetero/homosexual figure as a power/knowledge regime that shapes the 
ordering of desires, behaviors, and social institutions, and social relations - in a word, the constitution of the self and society. (Seidman, 1995, p. 128)

Conceptually aligned with postmodernism, Dilley (1999) determined three tenets to studying queer theory. First, queer theorists examine lives and experiences of those considered nonheterosexual. Secondly, queer theorists explore the juxtaposition of those lives/experiences with lives/experiences considered "normal." Finally, queer theory researchers are responsible for examining how/why those lives and experiences are considered outside of the norm. In short, as mentioned by Young, "Queer theory is about disrupting various regimes of normal, problematizing heteronormativity and critically examining sexual and gender binaries" (as cited in Manning, 2020, p. 416).

Queer theory is used in qualitative research across academic disciplines. Communication scholars claim that more communication research should embrace the call to assume a social constructionist perspective (Manning et al., 2020). Thus, the present study answered the call and utilized queer theory to analyze jealousy expression in romantic relationships.

While queer theory is useful in scholarly work, the most notable flaw is the hidden homosexual norm within queer theory (Gustavson, 2009). Even as queer theory attempts to deconstruct essentialist gender categories, academic communication research fails to study the theoretical implications of non-monosexuality (Thorne, 2013). Monosexism is "the assumption that one must be either heterosexual or homosexual" (Borver et al., as cited by Thorne, 2013). While scholars published multiple groundbreaking works on bisexuality in the years following the emergence of queer theory (Thorne, 2013), research focusing on the identity of bisexuality still falls far behind the study of homosexuality (Kulick, 2000). 
Additionally, even within queer theory, there is inequity regarding the representation of diverse identities and the implementation of intersectionality. Johnson (2001) stated that, "while queer theory may offer a progressive and sometimes transgressive politics of sexuality, the seams of queer theory become exposed when the theory is applied to identities around which sexuality may pivot, such as race and class" (p. 5). In short, Johnson is outlining that queer theory, while inclusive in its intent, is not without its own biases and flaws. One's experience of queerness intersects with other aspects of one's identity and therefore cannot be looked at as a universal experience (Manning et al., 2020). For example, one's experience of oppression and "othering" as an Atheist Black Lesbian is potentially vastly different than the experience of someone else being a Pansexual Native American Man. This differentiation in experience being the case, it is critical for scholars to emphasize the differences within the utilization of queer theory. Because this imbalance in representation reflects the current status of the use of queer theory, the present study endeavors to aid in the further expansion of queer theory by studying sexual orientations that do not fall under monosexist ideals.

\section{Bisexuality/Pansexuality and Jealousy Expression}

In this study, the researcher chose specifically to study the lived experiences of bisexual and pansexual individuals. Unfortunately, individuals who are attracted to people of more than one gender identity often deal with social implications of monosexism. Specifically, monosexism can result in binegativity and/or biphobia (Thorne, 2013). Binegativity is the "the structural oppression that bisexual people experience" (Obradors-Campos, 2011, p. 223), whereas biphobia is experienced on an interpersonal level and is "the fear of intimacy and closeness to people who don't identify with either the hetero- or homosexual orientation" (Ka'ahumanu \& Hutchins, 2015, p. 369). 
Negatively driven beliefs about the bisexual and pansexual identity are not just present among individuals who identity as heterosexual. The ostracization of the bisexual and pansexual identity is also present within the queer community, as noted in critiques of queer theory (Dilley, 1999). Bisexual and pansexual individuals have been made the "queer among queers, queer among straights, and just plain queer" (Ka'ahumanu \& Hutchins, 2015, p. 364). The three primary claims that people in the gay community make against bisexuality and pansexuality are that these identities are transitory, transitional, and/or merely do not exist. In lay terms, some claim that identifying as bisexual or pansexual is merely a "phase" that someone is going through, a temporary cover-up for being homosexual, and/or just homosexual denial (MacDonald, 1981). This "homosexual-heterosexual binary opposition continues to be the primary understanding of difference," thus leaving bisexual and pansexual individuals in a middle ground (Gustavson, 2009, p. 407).

Because there are social differences regarding the perception of bisexuality and pansexuality, the prevalence and construction of the bisexual identity/experience is growing to be a topic of much interest and debate in academia (Ding \& Rule, 2012). However, as mentioned, it has historically been a commonly held practice, even among researchers, to think of sexual orientation as a dichotomy, composed of gay and straight orientations (Weinberg et al., 1995). This being the case, there is a significant gap in academic literature regarding bisexual and pansexual identities. What research there is reaffirms that monosexist individuals continue to dichotomize the sexual orientation of bisexual and pansexual individuals (Esterline \& Galupo, 2013). Specifically, bisexual men are more likely to be described as gender nonconforming and "really gay." Controversially, female bisexuals are more likely to be seen as sexy and "really heterosexual" (Esterline \& Galupo, 2013). This perception of women bisexuals being sexy is 
often depicted in pornography and can be somewhat explained by male eroticization of female same-sex sexuality (Yost \& Thomas, 2012).

Because the very sexual orientation of individuals who are not monosexual is still under criticism, romantic relationships involving bisexual and pansexual individuals in United States are rarely studied. With over 9 million LGBTQIA+ community members in America as of 2011, and individuals who identified as bisexual being the largest recorded population within the community (Gates, 2011), there is a large presence of bisexual and pansexual lived experiences to consider.

As previously noted, the present study intended to address the following theoretical question: If jealousy experience is impacted by sexuality, and jealousy expression has predominantly been studied through the lens of heterosexual norms, could jealousy expression within queer relationships be different than that in heterosexual relationships? This study endeavored not only to address this gap in jealousy expression literature, but also to mitigate the lack of research dedicated to addressing the bisexual and pansexual communities' experiences in dyadic romantic relationships.

The bisexual and pansexual face a number of negative assumptions about their sexual orientation, including beliefs that they are non-monogamous, unfaithful, sexually risky, and more likely to spread STIs (Spalding \& Peplau, 1997). As the bisexual and pansexual community is faced with cultural assumptions about their sexual orientation (Rust, 1996), informed often by the media that perpetuate a generalized hypersexuality of those in the community, people who date bisexual or pansexual partners may have different experiences regarding romantic jealousy and therefore express their jealousy in different ways. Specifically, romantic relationship partners of bisexual and pansexual individuals may interpret their partners' sexual orientation to 
mean there are more "third-party threats" to their relationship. Unfortunately, given that jealousy expression can be both bright and dark sided (Guerrero, 2014), there are different consequences associated with the expression of romantic jealousy in under-researched romantic relationship dynamics. For example, a partner's expression of jealousy can range from constructive conversations to violent outbursts. Because research has shown how impactful mediating factors can be in jealousy expression, it is important to know how understudied mediating factors (in this case, sexual orientation) may relate to the presentation of jealous feelings. Henceforth, the researcher utilized queer theory as the framework to "queer" the study of jealousy expression. To this end, the following research questions guide the present study:

RQ1: How do romantic partners of people who identify as bisexual and pansexual express jealousy?

RQ2: What role, if any, do bisexual and pansexual individuals perceive that their sexual orientation plays in their partners' jealousy expression?

RQ3: What role, if any, does the gender identity of a perceived "threat" play in a partner's jealousy expression when one's romantic partner identifies as bisexual or pansexual? 


\section{CHAPTER III: METHODS}

\section{Recruitment/Participants}

Participants were at least 18 years old, identified as bisexual or pansexual, and had been in a dyadic romantic relationship with a partner who identified as someone attracted to a singular gender identity (e.g. straight, gay, lesbian), who was aware of the participant's bisexual or pansexual sexuality, and at some point in the relationship expressed romantic jealousy. IRB approval was obtained before any participants were recruited for the study.

\section{Procedures}

Participants were recruited through the Illinois State University communication research board (see Appendix A). Additional recruitment took place utilizing the researcher's email (see Appendix B) and social media (Facebook, Instagram, and LinkedIn) platforms (see Appendix C). Data collection for this study took the form of an online questionnaire constructed on Qualtrics (see Appendix D), an online survey software. The researcher chose to utilize an online questionnaire to prioritize participant quantity, as well as preserve participant anonymity. As the bisexual and pansexual communities are notably under-researched, the present study endeavored to add to the breadth of lived experiences considered when analyzing the experience of jealousy expression. Participants were informed that their involvement was voluntary and that they could terminated it at any point (see Appendix E). They were able to stop the survey at any time and still earn extra credit for completing it, for those taking the survey for extra credit. Participation was estimated to take approximately 20 minutes.

Participants' ages ranged from 18 to $65(M=22.73, S D=6.78)$. Of the 62 participants, six were men, four were non-binary, 47 were women, three were transgender men, one was gender fluid, and one chose not to identify their gender identity. Participants self-identified their 
race, and 50 were White, five were Hispanic, four were Asian, one was a biracial mix, one was Black, and one was Native American. Sexuality was also self-identified by participants, with 45 identifying as bisexual and 17 as pansexual. Of the 62 partners of participants, 44 were men, 16 were women, and two were non-binary.

\section{Data Collection Protocol}

Data collection for this study took the form of an online questionnaire constructed on Qualtrics. The questionnaire consisted of four different sections that included the following: personal demographics, partner demographics, jealousy expression examples, and general relationship observations. The first section included questions regarding the participant's demographic information (e.g., sexual orientation, race, gender identity).

The second section consisted of questions regarding the demographic information of the participant's partner and basic information about the romantic relationship. For example, the participant was asked about the nature of the relationship (e.g., seriously dating, engaged, married), length of relationship, and their age at the time the relationship began. All the questions about the participant's past partner and relationship aided in determining whether the themes emerging relate to sexual orientation and/or possibly other factors.

The third section was comprised of questions asking about the expressions of jealousy of past (monosexual) partners of the participant. This mixed methods section consisted of both open-ended questions and closed-ended items. The open-ended questions included items about the partner's expression of jealousy (e.g. When your partner expressed jealousy, what are things they would say? Would you consider your experience with jealousy as a bisexual/ pansexual individual average? Why or why not?). The closed-ended items were separate statements that utilized 5-point Likert-type answer options ( 1 = never, 5 = frequently $)$ and were based on 
examples from the Communicative Responses to Jealousy (CRJ) scale (e.g., violence, cheating, avoidance, direction conversation about jealousy) (Guerrero et al., 2011). For example, the participants were asked, "On a scale from one to five, how often did your past partner stop talking to you when they got jealous?" These questions were not meant to replicate the CRJ scale but rather to address different types of jealousy expression that the participant may have not have initially considered to be jealousy expression. Participants' scores on the items reflecting different types of communicative responses to jealousy were as follows: having a conversation about the jealousy, $M=2.84(\mathrm{SD}=1.28)$; flirting with someone else, $M=2.03(\mathrm{SD}=1.31)$; threatening to end the relationship $M=1.84(\mathrm{SD}=1.23)$; spying on/ stalking you, $M=2.13$ (SD $=1.46)$; becoming confrontational with the person they were jealous of, $M=1.65(\mathrm{SD}=1.08)$; denying feeling jealous, $M=3.08$ ( $\mathrm{SD}=1.81)$; cheating on you with another individual, $M=$ $1.84(\mathrm{SD}=1.29)$; making violent threats towards you $M=1.52(\mathrm{SD}=1.12)$; and avoiding you $M=2.71(\mathrm{SD}=1.36)$. While participants did not report experiencing most of these to a great extent on the quantitative items, the most reported one was denying feelings $(M=3.08, \mathrm{SD}=$ 1.38), and participants reported many of these communicative responses when answering the open-ended questions.

The fourth section consisted of questions asking about the participant's perception of the relationship and how different factors might have influenced the relationship and/or their partner's expression of jealousy. For example, the participants were asked to share if there was any reason for their partner to be jealous, if the participants thought that their sexual orientation played a role in their partner's jealousy, and if they perceived their experience with partner jealousy expression to be "normal." Finally, the participants were asked if they had any additional thoughts to share to end the survey. 


\section{Data Analysis}

To analyze data for RQ1, the researcher used Guerrero et al.'s (2011) CRJ scale as a framework. The open-ended responses were classified utilizing the four communicative jealousy response categories (i.e., constructive, destructive, avoidant, and rival-focused), and within the categories, the 11 specific communicative responses to jealousy. The researcher, utilizing deductive analysis, sought to understand whether the participants' experiences of partner jealousy expression fit within the categories and responses outlined by Guerrero and colleagues.

Inductive thematic analysis was conducted to determine the emergent themes for RQ2 and RQ3. As explained by Braun and Clark (2006), thematic analysis is used for "identifying, analyzing, and reporting patterns within data" (p. 79). Utilizing thematic analysis allows the researchers to "search for certain themes or patterns across an entire data set, rather than within a data item, such as an individual interview" (p. 81). Braun and Clarke's (2006) explanation of thematic analysis call for a six-step process that the researcher followed. First, the researcher collected and familiarized themselves with the data. Second, the researcher generated initial codes. Initial codes came directly from an identified segment of the written exchanges on the Qualtrics survey. Third, the researcher looked for similarities between the initial codes and separated/grouped them into potential themes. Then the researcher reviewed the potential themes. The researcher did this by checking the themes in relation to the initial codes and the data set as a whole. The researcher then defined and named each code after they were checked. The themes determined for RQ2 and RQ3 were highly influenced by queer theory and the call to examine if and how participants' lives and experiences are considered outside of the norm (Dilly, 1999). The themes for RQ2 were constructed with consideration of how participants' sexual orientations may influence partners' communicative responses to jealousy. To analyze the 
themes for RQ3, findings were first divided into sections based on participants' partners' gender identity and the gender identity of a perceived threat (e.g., women partners and men as threats, women partners and women as threats, men partners and women as threats). Within each partner/threat gender identity section, the researcher determined themes present in the participants' descriptions. Finally, the researcher wrote the final report. 


\section{CHAPTER IV: RESULTS}

\section{Communicative Responses to Jealousy}

In RQ1, the researcher asked, "How do romantic partners of people who identify as bisexual and pansexual express jealousy?” In their Communication Responses to Jealousy Scale, Guerrero et al. (2011) identified 11 different responses to jealousy, organized into four different categories: constructive, destructive, avoidant, and rival-focused. To understand the forms of jealousy expression experienced by bisexual and pansexual participants, the researcher categorized data into Guerrero and colleagues' categories and responses to jealousy. The four communication categories were present in participants' responses.

\section{Constructive Communication}

The constructive communication category includes integrative communication and compensatory restoration and is demonstrated by the partner communicating direct and positive messages (Guerrero et al., 2011). Constructive communication is often used when the partner is demonstrating an effort to make the relationship better and consists of integrative communication and compensatory restoration. There were few constructive communication strategy responses that solely reflected integrative communication but not compensatory restoration.

Integrative communication occurs when one attempts to problem-solve. This response can also include an effort to disclose feelings and concerns (Guerrero et al., 2011). There were very few examples of partners expressing jealousy using integrative communication Examples of this include when one participant (man, bisexual - note: identifiers after each participant reflect their reported gender and sexual orientation) reported that their partner would do "nothing at first, but later when we're alone she will casually bring it up, we'll talk about it, and act accordingly." Similarly, another participant (woman, pansexual) stated, "I think my experience 
[with jealousy] is fairly good because my partners have never been extremely jealous, and if there's an issue I feel like our communication if pretty good." While these responses do not outline specifically what the partners say, it appears that they privately and appropriately have a dialogue about the jealousy experience. However, as previously stated, there were few examples of responses that fit within this category.

\section{Destructive Communication}

The destructive communication category is comprised of negative communication, violence, and counter-jealousy induction (Guerrero et al., 2011). Destructive communication is demonstrated by the jealous partner being openly or indirectly hurtful (i.e., negative communication), making violent threats/actions toward the partner and/or objects, or attempting to make one's partner jealous by flirting or cheating. There were far more responses from participants that contained examples of destructive communication compared to constructive communication. These responses fall into several categories.

\section{Negative Communication}

Participants reported witnessing their partners displaying negative affect expression, defined as a nonverbal display of jealous-related emotions (e.g., frustration, sadness, or anger) (Guerrero et al., 2011). One participant (woman, pansexual) explained that, "when I told him there was a guy on my floor who gave me candy, I got an hour-long rant about how I didn't take into account his feelings at all when I interacted with acquaintances." Similarly, another participant (woman, bisexual) responded:

One time her [a friend of the participant] and I went to a bakery because he wouldn't take me there and I had no car. And when we got back he said something along the lines of 
"Oh so is she a better boyfriend than me?" And then asked if we were doing anything physically. Whole time, her and I are just friends.

In both of these responses, the participants are reporting that their partner expressed frustration and/or anger over what they considered very normal interactions they had with other people.

Some participants indicated that their partner would engage in negative communication but not about the jealousy itself. For example, one participant (woman, bisexual) shared that their partner "would get angry with me [about a situation of which they were jealous] and make an argument about something else," thus deflecting the topic of jealousy but still exercising negative communication.

\section{Violent Communication}

Violent communication expression is when a partner reaches the point of threatening or engaging in physical violence as a response to their feelings. Specifically, violent communication focuses on physically harming or threatening to harm the partner (Guerrero et al., 2011). Violence can come in the form of threats and actions. Participants reported both the threat of violence and acts of violence.

Violent Threats. Some participants shared that their partners engaged in making violent threats. One participant (woman, pansexual) shared that their partner would "insist that I am straight, threaten violence." Additionally, some violent threats were made not regarding violence towards the bisexual/pansexual partner, but rather toward the jealous partner themselves. One participant (woman, bisexual) shared that their partner was:

extremely suicidal and had been hospitalized three times before we dated. The reason our relationship lasted as long as it did was only because he threatened to kill himself if I 
dumped him. He was extremely possessive, thought that he owned me, and did not want me to talk to anyone besides him.

In this instance, the partner threatened self-harm. Similarly, another participant (woman, bisexual) shared that when expressing jealousy, the partner "would threaten to kill himself of self-harm, which was just as frightening as when they would threaten me." As shown, threats of violence could be made to the participant about their own safety or that of their partner.

Violent Actions. Additionally, violence can escalate past threats and become action. Participants reported experiencing violent actions. One participant (woman, bisexual) shared that their partner would "yell mostly, but one time I got shoved into a locker." Another participant (woman, bisexual) shared that their partner was "calling me every name in the book 'stupid bitch/slut who likes to be finger fucked' also started to throw items and stalk towards end of relationship." These responses demonstrate that violence can go beyond words and threats and escalate to physical engagement. These participants demonstrate how they are sometimes physically at risk when their partner expresses jealousy.

\section{Counter-Jealousy Induction}

Counter-jealousy induction includes trying to make one's partner more jealous than one is and/or trying to make one's partner feel guilty for their actions. This can also be referred to as manipulation (Carson \& Cupach, 2000). Several participants reported instances of experiencing counter-jealousy. One participant (woman, bisexual) shared that their partner would "try to make me jealous by bringing other girls, who had expressed their feelings to her at my job. Ignore my calls and messages to make me feel bad, although I had done nothing wrong." Similarly, another participant (woman, bisexual) shared that when: 
a girl I had hooked up with was at the party we were at, and she and I remain friends because it was more of a one time thing. He the whole night, was talking to girls that we weren't even friends with and in my opinion flirting with them.

As these examples outline, many participants experienced manipulation attempts that came in the form of their partners texting, talking, and flirting with people whom their bisexual/pansexual partners would perceive as threats.

These responses indicate that partners often utilized the destructive communication strategy to express jealousy in relationships involving one bisexual or pansexual person. In fact, participants reported more responses that fit in the destructive communication category than in any other any category. Examining negative communication, violent communication, and counter-jealousy induction, destructive communication reflects completely dark-sided behaviors. These data further reinforce that jealousy expression can be as simple as frustration or as dangerous as a threat to one's life.

\section{Avoidant Communication}

Avoidant communication includes being silent or making denials about the relationship and/or experience of jealousy (Guerrero et al., 2011). This category includes silence and denial. There were no responses that included explicit examples of denial. Denial as an expression of jealousy is when one "shuts down" communication that includes denying jealous feelings

(Guerrero et al., 2011). However, there were many examples of partners engaging in silence as a response to jealousy.

\section{Silence}

Silence reflects decreased communication, such as becoming quiet and not talking very much (Guerrero et al., 2011). One participant (transgender man, pansexual) who experienced 
avoidant communication stated that their partner would "pout" and give them the "cold shoulder." Similarly, another participant (man, bisexual) shared that their partner would "give a cold shoulder" and "not engage." According to a participant (woman, bisexual), one instance of avoidant communication to distance occurred when:

I hung out with a female friend who is also bisexual \& has expressed interest in me at a small gathering (part of a small friend group I formed here at ISU) and was sending selfies and texts throughout the night. He saw her in one of them and got upset, started sending "k" "lol" and other short texts before completely ignoring me and then ranting about it to me the next day and telling me to tell him that he's the only one I want and stuff along those lines. I am flattered by my friend thinking I'm attractive, but didn't do anything sexual with her.

While this example later escalated into negative communication, the initial response to the feeling of jealousy was to minimize and then cut off any kind of communication. Many instances of active distancing were conveyed through nonverbal communication. In a similar example, another participant (woman, bisexual) shared an example where they:

went to Six flags and was having a GREAT time because we both love height and anything with a thrill to it. When we got off the Superman, we started to race to the next ride and accidentally as we rounded a corner, me and another girl with her friends crashed into each other and her nachos got all over my shirt. Of course this was my fault for not paying attention, but she tried her best to get the cheese sauce off of my shirt and offered me her flannel to wear and keep in return I buy her more nachos, now you would think this would be a hilarious situation, which it was except one person didn't agree with how close I was getting to a “ overly friendly stranger”. After I took her flannel Jonnie 
and I started walking towards to next ride, however when we got there he got into a different car with another group while the employee had to pull someone in line to ride with me. For the rest of the time that night he went to separate rides without me. It's a tradition between us that we get a funnel cake before we leave the park, so I told he to meet my by the shop. . . . He texted back: I am outside the gate. . hurry up. As you can imagine the whole car drive back to Bloomington was silent (literally with not music!). In this particular response, the participant outlines how their partner nonverbally and verbally distanced themselves from them. They physically put space between the two of them and also refused to engage in "normal" conversation and/ or routines.

Thus, while silence and denial can both reflect avoidant communication, participants tended to recall silence in detail but not denial. Their examples of silence included a decrease in verbal communication but also an increase in physical distancing.

\section{Rival-Focused Communication}

Rival-focused communication includes enacting surveillance, contacting rivals, exhibiting signs of possession, and rival derogation (Guerrero et al., 2011). Participants recalled all four responses to jealousy.

\section{Surveillance}

Surveillance behavior includes intentionally observing one's partner (e.g., spying, checking the partner's whereabouts, looking through the partner's possessions) (Guerrero et al., 2011). One participant shared that their partner (woman, bisexual) would "look through my phone and personal belongings." Another participant (woman, pansexual) shared that their partner would "monitor my internet usage and ask a lot of questions while I was out."

Additionally, one participant shared that their partner went so far as to record them. Specifically, 
the participant (woman, pansexual) reported that "well, for one thing, he set up a tape recorder to record me in the apartment when he wasn't home." Other examples of surveillance include one participant (nonbinary, pansexual) who shared that their partner "would yell and accuse me of cheating every time I brought up being lonely and wanting friends. One time he went so far as to check every message on my phone and Playstation.” These surveillance behaviors seem to illustrate that participants' partners needed validation that the participant was not behaving in a way they deemed inappropriate or that warranted jealousy.

\section{Rival Contact}

Rival contacts involve one communicating with, and often threatening or warning, the "rival" (i.e., the threat) (Guerrero et al., 2011). There were very few instances of participants reporting a partner's rival contact engagement. However, one participant (woman, bisexual) shared that their partner would "Talk to me or be passive aggressive towards the other person." Additionally, another participant (woman, bisexual) reported that, because their partner felt "threatened around females. He would be rude to them and then ask me if I thought they were hot." While these examples do not display outright aggression, the passive-aggressive communication can still indicate an awareness of the threat. Other than responses indicating passive responses, direct rival contact was not a common strategy that participants reported.

\section{Signs of Possession}

Signs of possession include publicly displaying the relationship to others, so they know the partner is taken (Guerrero \& Andersen, 1998). People can demonstrate possession both verbally and physically. This communicative response to jealousy was not initially part of Guerrero and colleague's (1995) CRJ scale. However, in revisiting the CRJ Scale, Guerrero and 
Andersen's (1998) later work suggested that this response be included in the scale. One participant (woman, bisexual) shared an instance where:

He was really mad at me when I did not answer his texts because I was talking to one of my guy friends who just found out he was moving across the country, he showed up at my dance studio because he was jealous that I was spending more time with my female dance friends than him during classes.

Similarly, another participant (woman, bisexual) shared that "when we went Christmas shopping she got jealous of the worker how was helping me find a present for my sister so she started getting hands and clingy in front of the worker." In another participant's (woman, bisexual) experience, "if I sat near my friend instead of him, he'd pull me away. If I walked next to my friend, he would grab my hand and pull me to the other side of him.” All of these responses outline how their partners would publicly perform intimacy and/or attentiveness to make "threats" aware of the relationship.

\section{Rival Derogation}

Derogation of rivals occurs when people try to lessen the value of rivals by criticizing or making negative comments about them in front of the partner (Guerrero et al., 2011). This communicative response to jealousy was not initially part of Guerrero's 1995 CRJ scale. However, in revisiting the CRJ Scale, Guerrero and Andersen's (1998) later work suggested that this response be included in the scale. In the data, there appeared to be almost the opposite occurring. Participants' partners would ask if they thought other people were attractive. For example, one participant (woman, bisexual) shared that their partner would ask, "Are you staring at them because you like them? Do you find her more attractive then me?" Another participant 
(genderfluid, pansexual) reported that their partner would repeatedly ask "if I thought a girl was hot."

A number of participants explained that, instead of degrading a threat, their partners would need clarification if their bisexual or pansexual partner perceived the other person as attractive in the first place. One participant (woman, pansexual) shared that their partner would ask about the origin of their sexual orientation and if it was tied to anyone. Specifically, the partner would "continually ask if certain people made me think I was pan. Always asked if 'something happened' and who made me feel this way." The researcher included these responses here because they related to asking questions and commenting about a potential rival, and because participants provided these examples when asked to recall jealousy expression. However, these examples may be better described as trying to understand who was worth being perceived as a rival.

By asking RQ1, the researcher wanted to understand if jealousy expression in relationships involving one bisexual or pansexual person could be categorized using the communicative responses to jealousy from the CRJ. Undeniably, the results consisted of examples from all four categories. Although participants recalled more responses that fell within the destructive and rival-focused categories, the constructive and avoidant strategies were also represented in the data to a lesser extent.

\section{Perceived Impact of Sexual Orientation on Jealousy Expression}

In RQ2, the researcher asked, "What role, if any, do bisexual and pansexual individuals perceive that their sexual orientation plays in their partners' jealousy expression?" In the following section, I outline how a bisexual or pansexual partner's sexual orientation elicits two primary responses from their monosexist (i.e., only attracted to one gender identity) partners. 
Specifically, I will demonstrate how participants' partners demonstrated monosexist misinformation and decreased trustworthiness.

\section{Monosexist Misinformation}

Participants reported that their romantic partners would cite inaccurate information about bisexual and pansexual orientations as explanation for their jealousy expression. Specifically, participants reported that their partners assumed their sexual orientation meant they were attracted to everyone and that partners had an inaccurate understanding of the LGBTQIA+ community as a whole.

\section{Attracted to Everyone}

Many participants explained that their monosexist partners assumed that because they could be attracted to multiple gender identities, that meant that they would automatically be attracted to everyone. Specifically, many partners appeared to believe that the possibility for attraction meant the guaranteed feeling of attraction. For example, one participant (woman, bisexual) shared that their partner would say, "I don't understand how you can like both men and women, you must really like everyone." Another participant shared that their sexuality "has been used against me a lot because it's 'hard to adjust to someone thinking everyone is attractive' which is invalid because that's just not how it works." Additionally, one participant (woman, pansexual) shared that:

I was telling him and a close friend about how I am in a better mental health place after finally learning my sexuality. In public in front of my friend he asked who made me this way. He has always refused to use the word pansexual or acknowledge that learning about myself has been good for me, and instead treated it as a reminder that I could love other people. 
This assumption of attraction to everyone seems to further display the real-life impact of the hyper-sexualization of bisexual and pansexual individuals.

Consequently, participants shared that their romantic partners reported an increase in perceived threat as motivation for their jealousy expression. Participants reported that their partners would openly confess that they were aware of how many more "threats" there were to be aware of because of their partners' bisexual or pansexual orientation. One participant (woman, pansexual) shared that their partner would "say that it was too many people to like as if that mattered." Another participant (woman, bisexual) reported that their partner "would always say that there is more for him to worry about." The idea that their partner could be attracted to anyone made partners aware of just how large their "threat pool" was.

\section{Misunderstanding the LGBTQIA+ Community}

Participants also reported instances in which their monosexist partners did not understand what it meant to be a member of the LGBTQIA+ community, and more specifically did not understand the non-monosexist members of the community (e.g., bisexual, pansexual). One participant shared their experience:

Anytime it [jealousy] came up he would act like there was someone pulling me over to the gay side. There didnt need to be anyone to blame, like before I knew my sexuality, it was just the general lgbt population that he acted like was pulling me away from him. It very clearly contributed to his hatred and unacceptance of lgbt+ people. Most of the time if I brought up anything about my sexuality or lgbt+ support, he would completely ignore my comments and roll his eyes, walk away, or change the subject.

These examples of monosexist misinformation seem to suggest that monosexist partners may not fully understand what it means to be bisexual or pansexual, nor what it means to be a part of 
those communities, which participants perceived as contributing to the partners' feelings and expression of jealousy.

\section{Decreased Trustworthiness}

Participants reported that their partners would cite their sexual orientation as a reason to believe they were less trustworthy. This criticism of trustworthiness came in the form of critiques of observed actions and hypothesized cheating. For example, one participant (nonbinary, pansexual) shared that their partner "assumed it [their sexual orientation] meant I wanted to automatically sleep with anyone willing to be nice to me." Similarly, another participant (woman, bisexual) reported that:

To me it seemed as if he used it [their sexual orientation] as a way of thinking I was talking to other people while we were dating even though it was just my sexual orientation that people knew about and not me actually going to other people in a flirtatious manner.

A number of participants shared that their partners used their sexuality as an explanation for why they feared they would cheat. One participant (woman, bisexual) shared that their partner said that:

because I liked women, I liked all my friends who were girls romantically, and therefore could not be trusted to be alone with them. He also said that because I was bi I would definitely want a polyamorous relationship and cheat on him with other men.

Similarly, another participant (female, bisexual) reported that their partner "would often humiliate me for my sexuality in front of his sister saying it's 'unnatural' and that he can't trust me since apparently I'm 'more likely to cheat' since I am not straight." These examples illustrate that monosexist partners can assume that sexual orientation correlates with lack of loyalty. 
To reiterate, in RQ2, the researcher asked: What role, if any, do bisexual and pansexual individuals perceive that their sexual orientation plays in their partners' jealousy expression? Participant responses indicated that there were two primary ways their sexual orientation impacted their partners' jealousy expression: monosexist misinformation and an increased assumption of untrustworthiness. Monosexist misinformation consisted of participants' partners believing that their bisexual or pansexual partner is attracted to everyone and that the LGBTQIA+ community tries to monopolize and pull their partners away. Decreased trustworthiness is the belief that due to the larger "threat pool," their bisexual or pansexual partners are more likely to be disloyal in the relationship.

\section{Gender Identity and Perceived Threat}

In RQ3, the researcher asked, "What role, if any, does the gender identity of a perceived 'threat' play in a partner's jealousy expression when one's romantic partner identifies as bisexual or pansexual?" Participants reported that their romantic partners had various reactions to different gendered relationship threats (e.g. man, nonbinary, woman). I divided each section below into the gender identity of the monosexist partner and the reported perception of different gender threats. While some participants did not recall any jealousy expression based on specific gender identity threats, many participants were able to recall these types of threats. Further, the participants reported on a significantly higher number of partners who were men, rather than women or nonbinary. This being the case, the results tend to focus more on partners who were men. In the following sections, the researcher outlines how different gendered partners reportedly reacted to different gender identity threats. 


\section{Partners Who Were Men}

Some participants who reported that their partners who were men shared that their partners were threatened by both men and women.

\section{Men as the Threat}

Participants provided two primary explanations for why they believed men elicited their partners' jealousy expression: knowledge of how other men behave and lack of concern for threats who were women.

First, participants believed that their partner's jealousy expressions were rooted in how upfront and forward they suspected other men would be with their partner. Specifically, many participants reported that their partners expressed awareness of how other men would express interest and/or engage with them. For example, one participant (woman, bisexual) shared that their partner expressed jealousy "typically around men, he tends to be more aggressive towards men when they compliment me than he does to women." Another participant (woman, bisexual) explained that their partner "would always ask about my guy friends, and wouldn't back off even if I had either expressed my friendship, or had proven that some friends were not attracted to women." This response indicated that the participant felt that explaining the "male threat's" sexual orientation (i.e., not attracted to woman) would act as a buffer for their partner's jealousy. Finally, one participant (transgender man, pansexual) shared that their partner:

wouldnt admit it but there probably was more upset with me hanging out with men. I think he felt like men were more likely to make advances on me if they liked someone whereas women probably wouldn't be as upfront.

Considering the responses, it appears that some men express jealousy because of their awareness of how other men can or will potentially pursue their partner. 
Several participants also noted that their partners expressed a complete lack of concern for women as possible threats in their communication of jealousy. For example, one participant (woman, bisexual) shared that their partner told them that "if I ever cheat on him he would rather it be a woman, not a man." This participant noted that "he's joking but it's pretty telling I think." Additionally, one participant (nonbinary, pansexual) explained that their partners' jealousy towards males was in contrast to the fact that they would also be interested in sexually engaging with a female threat. Specifically, they stated that "male or male presenting people triggered him. But it he thought maybe he could get a threesome with another female he was on board." As exemplified, some partners who were men would only get jealous of other men because they did not perceive women to be as much of a threat.

\section{Women as the Threat}

Participants also shared examples of their partners who were men expressing jealousy about threats who were women and provided three possible reasons that their partners who were men expressed jealousy toward threats who were women. These three explanations include feelings that women were "more attractive" threats, they could not "compete" with women, and that partners' attraction to the same sex would elicit homosexual actions.

First, some responses consisted of reasoning that was rooted in previously researched jealousy motivation, specifically the idea that a threat may be perceived as more physically attractive by their partner. For example, one participant (woman, pansexual) reported that their partner "was more threatened by females, regularly telling me that I couldn't hang out with my best friend because she fit a basic description of the kind of women, I would consider attractive." In this case, the participant explained that their partner's jealousy was motivated by knowing their partner's "type" and seeing that their friend fit that description. However, other participants 
explained that their partners do not know their "type" and therefore would question who their partners" "type" was. One participant (woman, bisexual) noted that their partner was "more threatened around females," stating that "he would be rude to them and then ask me if I thought they were hot."

Second, participants explained that partners who were men expressed jealousy regarding women because they felt that they could not "compete." For example, one participant (woman, bisexual) stated that their partner was "equally jealous of both sexes, but he felt more threatened by girls because he wasn't one.” In another participant's experience, (woman, bisexual) experience, their partner would:

Ask about a friend over and over (why they were talking to me, especially if they texted later at night), say many times that he was worried I was going to leave him because I "might actually be a lesbian," even when I explicitly stated that this is SUPER biphobic and it bothered me that he said that, specifically bombard me with questions on if I actually liked his genitals.

This specific example draws an interesting parallel between the perception of sexual orientation and genitalia. The partner appeared to believe that seeking validation for his genitals would somehow reaffirm that his partner was not "actually a lesbian," as women cannot offer the same genitalia as that of a man. This is, however, operating under a cisgender assumption about sex and gender identity. While the perception of needing to compete was not a highly demonstrated explanation for jealousy expression, it does display that partners can be jealous because they do not "have to offer" what the other gender identity supposedly can contribute. Unfortunately, these responses could not concretely clarify what the participants' partner perceived as a difference (e.g. anatomy, communication skills, relatability). 
Lastly, men perceived women as a threat because they did not want the participant to be "gay." The partners' jealousy seemed to have nothing to do with a specific woman as a threat, but rather the fact that if a woman was flirting with/pursuing their partner (who was also a woman), that means that their partner would have a chance to "act gay." Specifically, participants reported on how their partners would utilize delegitimizing language and biphobic arguments to explain their feelings about threats who were women. Biphobic arguments are rooted in binegativity and/or biphobia (Thorne, 2013). To reiterate, binegativity is "the structural oppression that bisexual people experience" (Obradors-Campos, 2011, p. 223), whereas biphobia is experienced on an interpersonal level and is "the fear of intimacy and closeness to people who don't identify with either the hetero- or homosexual orientation" (Ka'ahumanu \& Hutchins, 2015, p. 369). Examples of this mindset from the data include one participant's (woman, pansexual) explanation:

I think w(h)e was uncomfortable with me having close female friends, because that to him was a potential space for me to act "gay" which was all pansexual meant to him when I explained it. I could tell because he was always pressuring me to hang out with his male friends and him together. Those times were always fine, but he explicitly was not supportive of me having female, woman, or lgbt friends.

Similarly, other participants shared that their partner reported not being jealous of women but were rather non-believing of their partners' attraction to women altogether. For example, one participant (woman, bisexual) shared that:

My partner got more threatened by men in actual life (more threatened if men were texting me/hanging out with me) but more threatened by the idea of me "actually being a lesbian" rather than the idea of me being with a man. While it might sound nice that he 
was less so threatened by the women in my real life (sometimes, but not always) that still felt super invalidating of my sexuality because if you see my sexuality for what it truly is but you're going to get threatened by only one of the genders I am attracted to then do you really see me as bisexual?

Another participant (woman, bisexual) shared:

I would say it [jealousy] probably happened a little bit more than average because there is the occasional incident where he also got threatened by women, but I would say that it is especially different than average because sometimes his jealousy would imply that he doesn't really have to be threatened by women which is invalidating to the part of me who is attracted to women (I assume most bisexual/pansexual women experience this when they are in a $\mathrm{m} / \mathrm{f}$ relationship tbh. I have three other bi/pan friends and all them them have experienced this in all $\mathrm{m} / \mathrm{f}$ relationships where they were out to their partners). And then also it is different from average because of the underlying tone of "I am going to lose you to women as a whole b/c you might actually be a lesbian" versus with men where its like the specific men that he was worried about, not men as a whole.

A final example of a response including biphobic sentiments is when a participant (woman, bisexual) shared that:

He complained about me hanging out with girls and having sleepovers with them, but only got really angry about other men. He said me flirting with a girl was not as valid or real as if I were to flirt with a man.

These three extensive examples outline how some men were not actually concerned with women as threats to their relationship but rather the threat of their partner having homosexual attraction. 
Ultimately, participant responses indicate that do perceive threats differently based on the participants' gender identity. It was reported that men were perceived as threats by other men because of their boldness. At the same time, women were perceived as threats by men because a bisexual or pansexual partner may perceive them as more attractive, may have needs fulfilled by them in ways a man cannot, and may provide an opportunity for the bisexual or pansexual partner to act "gay." However, some participants also noted that women were not seen as threats but rather as potential threesome partners. In short, the data do indicate that gender identity plays a role in how men perceive and make sense of a relationship threat.

\section{Partners Who Were Women}

Some participants reported that their partners who were women were threatened by men and women, with participants recalling more experiences related to men as threats compared to women.

\section{Men as the Threat}

Participants shared examples of their female partners expressing jealousy about male threats. Many responses from participants regarding their partner feeling threatened by men were fairly general. For example, one participant (woman, pansexual) mentioned that her partner was “only threatened by men, she would say so." Another participant (transgender, pansexual) stated that their partner would feel "threatened" by men. Some responses indicated that female partners got jealous of men specifically if the participant had previously displayed an interest in men. For example, one participant (woman, bisexual) mentioned that their partner addressed her lack of comfort with her working with men. Specially, the participant's response read:

I'm the only female in my department in mechanics at work, and having my previous partners being a male she wasn't comfortable with me working with men. As a form of 
greeting we high five or give a side hug at work and although she was in a different department I wouldn't do the same to her as a form of professionalism seeing as everyone knew we we're together. So she would just bad mouth me to her coworkers and not talk to me till the following day.

A similar response was provided by another participant (woman, pansexual). The participant stated that her partner was "way more threatened by male presenting since she knew I leaned towards masculinity." These responses indicate that some women feel threatened by individuals who align with their bisexual/pansexual partners previous "types." Specifically, partners appeared more prone to awareness of threats who were men when their partner had history with and/or had expressed interest in men.

\section{Women as the Threat}

Additionally, participants shared examples of their female partners expressing jealousy about threats who were women. Of the participants who referenced this specific dynamic, one was a man and one was nonbinary. There was very little explanation as to if or how women expressed jealousy regarding other women as threats. The only two provided responses read "she was more threatened around girls" and that "felt more threatened by women." While there are not many responses regarding this particular gender dynamic, the results do indicate that women can perceive other women as threats.

\section{Partners Who Were Nonbinary}

Interestingly, most participants could not recall any instances of jealousy expression by nonbinary partners. One participant (woman, bisexual) did share that their nonbinary "partner definitely seemed more threatened around males because it seemed as though they didn't really take my sexuality seriously to the point where they didn't even consider females on the same 
level as a threat." This response further reinforces that regardless of gender, partners sometimes questioned and delegitimized their bisexual/pansexual partners' sexual orientation.

Through RQ3, the researcher explored the differences of threat perception and jealousy expression through the lens of gender identity. The data indicate that when one is in a relationship with a bisexual or pansexual individual, gender identity plays a role in how one might perceive a potential threat. Whether it is a man fearful that being around a woman may "turn" their girlfriend gay, or a woman concerned that their partner's "type" might actually be men, the data demonstrated that gender identity plays a role in jealousy expression. 


\section{CHAPTER V: DISCUSSION}

The purpose of this study was to explore and better understand how bisexual and pansexual individuals have had jealousy expressed to them by monosexist partners. In this study, the researcher utilized queer theory and Guerrero's (1995) Communicative Responses to Jealousy Scale to analyze jealousy expression in relationships where one partner identifies as bisexual or pansexual. The study endeavored to challenge traditional notions of relationships because, although there has been extensive research conducted on jealousy and jealousy expression, few studies address how the communicative experience may be different for nonmonosexist identities. Additionally, as jealousy and jealousy expression can be both bright sided and dark sided (Guerrero, 2014), it is pertinent that we address the differences in these communicative exchanges to further understand the risk and benefits of experiencing jealousy expression within these dyadic romantic relationship dynamics.

The researcher used Guerrero et al.'s (1995) Communicative Responses to Jealousy Scale to analyze data for RQ1 and to understand the types of communicative responses to jealousy that bisexual and pansexual participants received. RQ2 and RQ3 were driven by queer theory and sought to uncover the role that participants believed that gender identity played in the partners' expression of jealousy and the identification of who is considered a "threat" in these romantic relationships.

\section{Summary of Findings}

In RQ1, the researcher asked: How do romantic partners of people who identify as bisexual and pansexual express jealousy? From the responses, the researcher categorized the responses utilizing Guerrero et al.'s (1995) CRJ Scale. The responses were divided into four communication strategies: constructive, destructive, avoidant, and rival-focused. Within these 
four strategies, responses were broken down into 14 jealousy expression categories, 11 from the original scale and three that were later added. Constructive communication strategies were the least reported strategy. Specifically, within the constructive communication strategy, there was only one example of integrative communication. The other communication strategies were reported at much higher rates.

Within the destructive communication strategy, there were examples of negative communication, violent communication, and counter-jealousy induction. Regarding negative communication, participants reported their partners displayed anger and frustration. Other participants shared that their partners' jealousy expression surpassed negative communication and moved to violent threats and actions. Participants reported that these threats and actions, while often directed at them (i.e., the participant), were sometimes communicated as threats to the partners themselves. That is, some participants reported that their partners would threaten self-harm and/or suicide. Finally, participants reported experiencing counter-jealousy induction: Participants reported that their partners attempted to make them jealous after witnessing them chatting with friends or even being at the same party as an ex-partner.

Within the avoidant communication strategy, there were primarily examples of silence. Participants reported that their partners would become reserved/removed after witnessing them interact with other people whom they deemed as threats. Henceforth, their silence would come in the form of limited verbal and nonverbal communication. Some partners stopped responding to texts, and others would physically remove themselves from being around their partner.

Within the rival-focused communication strategy, there were examples of surveillance, rival contact, signs of possession, and rival derogation. Examples of surveillance ranged from participants' partners checking their phones to audio recording them without their knowledge. 
Participants did not report experiencing many rival contacts. In fact, the only rival contact reported was a partner acting passive-aggressively towards the "threat." There were, however, many examples of partners utilizing a possessive communication strategy. Specifically, participants reported how their partners would utilize physicality to indicate their relationship with them. Examples of this behavior included pulling their partner closer and visiting the locations they knew their partner would be interacting with potential threats. Finally, participants reported experiencing rival derogation, although not in the typical way. Instead of partners criticizing threats, participants reported that their partners were more concerned with knowing if their partner thought the threat was attractive.

In RQ2, the researcher asked: What role, if any, do bisexual and pansexual individuals perceive that their sexual orientation plays in their partners' jealousy expression? The responses fell into two themes: monosexist misinformation and decreased trustworthiness. Within the theme of monosexist misinformation, responses centered on two beliefs: that bisexual/pansexual people are attracted to everyone and that the LGBTQIA+ community is something of which to be cautious. Participants reported that many of their partners misunderstood what being pansexual or bisexual meant. Many participants reported that their partners would say that, because the participant could be attracted to everyone, they would be attracted to everyone, thus increasing the partners' perceived threat pool. Additionally, many partners reportedly felt negatively about their partner's relationship with the LGBTQIA+ community. With many monosexist partners not believing in their partner's sexual orientation, they would articulate fears about LGBTQIA+ individuals turning their partner "gay."

The theme of decreased trustworthiness was deemed necessary due to the number of responses mentioning monosexist partners who articulated being concerned about their partners' 
ability to be loyal. Specifically, participants reported that their partners would say that being bisexual/ pansexual meant that they would definitely want a polyamorous relationship and/ or that they would automatically want to sleep with everyone. The assumption of hypersexuality reaffirmed the partner's predisposition to perceive everyone and anyone as a potential threat. Thus, partners' discomfort with the size of the threat pool translated into them questioning the participant's ability to remain loyal in the relationship. This sentiment was repeated across several participants' responses.

Finally, in RQ3, the researcher asked: What role, if any, does the gender identity of a perceived “threat” play in a partner's jealousy expression when one's romantic partner identifies as bisexual or pansexual? The data indicated that there are differences in threat perception when there are different gender identities. The results section regarding RQ3 was divided into gender identity of the partner and the gender identity of the threat.

Participants primarily reported that their partners who were men expressed jealousy about other men because they feared that men would be bold enough to "make a move" on their partner. There were minimal examples outlining how men were threatened by women. In fact, a few participants reported that their partners had said that if they had to cheat, they would prefer the participant cheat with another woman. Participants explained that their partners said this in the hope of participating in a threesome and/or because they did not view women as valid threats. However, some participants reported that their partners felt threatened by the idea of their partner being with another woman, not because of the particular woman, but because their partners were scared of them acting gay.

There were also examples of women partners seeing men as more of a jealousy threat, specifically when they were aware that their partners had previous experience and/or interest in 
men. The preexisting knowledge that their bisexual or pansexual partner had a previous interest in men appeared to threaten women partners. There were also examples of women being threatened by other women. Unfortunately, the participants did not explain these experiences. Nevertheless, the results do indicate that women can perceive other women as threats. Finally, there were minimal examples of nonbinary partners expressing jealousy towards threats of any specific gender identity.

\section{Research Conclusion and Implications of the Study}

There are many important conclusions to make from the data presented thus far. In the following sections, the researcher outlines these conclusions. The conclusions include queering the study of communication, addressing gender identity feedback, and exploring the absence of constructive jealousy. The researcher then discusses practical applications of this study that include increasing partner awareness, addressing the safety of bisexual and pansexual individuals, and addressing stigma in the LGBTQIA+ community.

\section{Queering the Study of Jealousy Expression}

One of the three tenets of queer theory calls scholars to examine how/why queer lives and experiences are considered outside of the norm (Dilly, 1999). Because the "norm" in much of queer theory literature is monosexist,this study challenges the homosexual norm within queer theory (Gustavson, 2009; Thorne, 2013). One goal of this study was to queer the scholarship on jealousy expression in hopes of analyzing the unique experiences of jealousy expressions in relationships in which one partner is bisexual or pansexual. Thus, in this section, the researcher will outline some important distinctions in jealousy expression for the population that was studied as these relate to existing research on jealousy. 
Participants from this study reported experiencing many of the jealousy expression strategies described in Guerreros and colleagues' (1995) CRJ scale. They provided extensive examples of their partners demonstrating destructive, avoidant, and rival-focused jealousy expression strategies. However, the specifics regarding how their partners displayed these jealousy expression strategies appear to be influenced by the participants' sexual orientation. The responses participants shared indicate that, when looked at through a queer theory lens, there are different understandings of certain relationship/jealousy terms utilized by participants and partners.

First, the researcher noted the alternative understanding of the term "type." It seems that often, when discussing romantic relationships between heterosexual couples, people use the idea of someone's "type" to reflect aesthetic and appearance factors (e.g. does the partner like someone tall and athletic, with brown hair?). However, in this study, the term "type" emerged as a way for partners to determine a participant's gender identity "preference." Monosexist partners demonstrated concern over understanding what their partner's "type" was. This lack of knowledge regarding their partner's "type" appeared to drive much of their jealousy expression when it came to understanding who a threat was to their relationship. Unfortunately, there is limited research outlining how the term "type" is utilized by partners of individuals who are bisexual/pansexual. As Gustavson (2009) explained, there is often an assumed homosexualheterosexual binary opposition that routinely places bisexual and pansexual individuals in an unknown middle ground. By understanding and accommodating for the different interpretations of who could be someone's "type", we begin to move away from the assumed homosexualheterosexual binary. 
Similarly, participants recalled that partners struggled with who they considered to be a rival/threat to the relationship. This concern over who to consider a threat was addressed in RQ2's theme of monosexist misinformation. The concern appeared to stem from an awareness of the increased rival/threat pool and the assumption that because their partner could be attracted to anyone, that all gender identity threats were valid. The very title of this study "it was too many people to like," a direct quote from a participant, indicates that participant's partner was not only aware of the increased threat pool but also daunted by it. In some instances, partners were able to articulate specific people as rivals/threats, but in other instances partners labeled entire gender identities as a rival/threat. For example, many participants reported that their partner would not want them spending time with women or men in general. The CRJ Scale (1995) defines jealousy as "when a person believes that a third party (sometimes called a "rival") threatens his or her romantic relationship in some way". While this definition does not consider the queered interpretation of the term, this study's findings indicate that adding a more specific definition for the term rival/threat may ultimately reap results that could reflect a more universal understanding of what/who a threat is.

Finally, some participants reported that their partners would utilize non-inclusive language when addressing their jealousy. In one participant's (woman, bisexual) experience, the language her partner chose to utilize further deepened his negative communication expression of jealousy. In her responses, the participant shared that:

One time her [a friend of the participant] and I went to a bakery because he wouldn't take me there and I had no car. And when we got back he said something along the lines of "Oh so is she a better boyfriend than me?" And then asked if we were doing anything physically. Whole time, her and I are just friends. 
What is notable is that her partner used the binary term "boyfriend." This not only negates the fact that the threat was a woman but further centers heterosexual language in the jealousy expression. In another participant's (woman, bisexual) experience, their partner would: Ask about a friend over and over (why they were talking to me, especially if they texted later at night), say many times that he was worried I was going to leave him because I "might actually be a lesbian," even when I explicitly stated that this is SUPER biphobic and it bothered me that he said that, specifically bombard me with questions on if I actually liked his genitals.

In this example, the participant reports that their partner brought up their own genitals and communicated a fear of the participant being lesbian. However, in many cases, an individual's genitals may not equate to their gender identity (i.e., the difference between sex and gender). In addition to assuming their partner would have a preference regarding gender identity and/or sex, the partner utilized heteronormative and cisgender language to determine the participants "actual preferences." Therefore, by asking these questions the way they did, the partner negated, perhaps subconsciously, the possibility, that the participant's attraction may not be based around one's gender identity/sex. It is notable that even amongst queer theory scholars, deconstructing essentialist gender categories proves difficult (Thorne, 2013). Additionally, the Communicative Responses to Jealousy Scale models the use of non-inclusive language. Within the scale, Guerrero et al. use dichotomous gender labels (i.e., he and she) that were not inclusive to individuals identifying as anything else. Ultimately, non-inclusive language is a challenge faced by many members of the LGBTQIA+ community, and the participants from this study were no exception. 
In short, factoring in bisexual and pansexual identities should change the way researchers analyze jealousy and jealousy expression data (Manning et al.'s 2020). While the term "boyfriend" or "girlfriend" may be merely a label in heterosexual relationships, it can be a way of disregarding the fact that one person could have relationships with boyfriends and girlfriends and should be addressed accordingly. Similarly, terms such as "type" and "threat," although universally understood in heteronormative and monosexist relationships, can mean something entirely different when looked at through the lens of queer theory.

\section{Gender Identity Impact}

Sexual orientation cannot be discussed without also taking into consideration the gender identities involved. This study's findings indicated that the gender identity of a perceived threat and the gender identity of the participant could impact a partner's jealousy expression. I provide some plausible explanations for these findings below.

First, the RTBM (Sagarin, et al., 2012) is an evolutionary model that proposes that sex differences in jealousy have developed in response to a reproductive instinct. In short, the RTBM predicts that the sexes will differ in their jealousy perception and responses regarding whether there is a threat of reproduction. When there is a threat of reproduction, partners will be more concerned with the sexual infidelity. When there is not a threat of reproduction, the partner will be more concerned with the emotional infidelity.

The data suggest that partners who were men expressed more jealousy toward other men who were potential threats. While participants did not explicitly state that their partners were concerned with reproduction via infidelity, it seemed that men were threatened by other men compared to other women, which may be tied somewhat to evolutionary perspectives of men pursuing women at all costs to reproduce. Partners who were men sometimes had a fear that men 
would more aggressively seek out their partners who were women compared to other threats who were women.

Some participants recalled that their partners directly communicated the preference for "them to cheat with women." These findings play into the social construction that lesbians can be viewed as a male eroticization of female same-sex sexuality (Yost \& Thomas, 2012). Rather than being genuinely attracted to another women, lesbian's sexual orientations are reframed to fit the monosexist narrative that they are all actually just hypersexual, and very sexy heterosexual women (Yost \& Thomas, 2012). Controversially, the findings of the present study demonstrate the notion that some partners believe that bi/pansexuality is transient and that women spending time with other women would result in a change in sexual orientation (Esterline \& Galupo, 2013; Gustavson, 2009). Specifically, women participants explained that their partners believed that they were not really bisexual or pansexual, but actually heterosexual or lesbian. The notion that individuals identify as bisexual/pansexual because they have not determined whether they are hetero- or homosexual yet was a monosexist assumption found in past research (MacDonald, 1981) and routinely displayed by participants' partners in this study.

Regarding the perception that bisexuality/pansexuality is a phase, there are three primary biases. These biases are that bisexuality and pansexuality are transitory, transitional, and/or merely do not exist. In lay terms, identifying as bisexual or pansexual is merely a "phase," a temporary cover-up for being homosexual, and/or just homosexual denial (MacDonald, 1981). However, this assumption of true homosexuality or true heterosexuality is not equally distributed amongst gender identities. Specifically, bisexual men are more likely to be described as gender nonconforming and "really gay." Controversially, female bisexuals are more likely to be seen as sexy and "really heterosexual" (Esterline \& Galupo, 2013). 
These responses demonstrate that bisexual/pansexual women are subject to assumptions about their sexuality by their own romantic partners. While these responses contradict the assumption that bisexual/pansexual women are automatically assumed to be heterosexual (Esterline \& Galupo, 2013), they do support the idea that partners assumed that the participants were actually monosexist. Additionally, partners who were men were concerned with their partners spending time with women, who would sway their emotional devotion and interest. They were not threatened by women because of the possibility of sexual infidelity but rather the idea that the participant being interested in women would change the participant's sexual orientation entirely. Some of these stereotypes and misunderstandings seemed to come to light in the data and may provide some explanation for the findings as they relate to gender identity differences with jealousy expression.

\section{Absence of Constructive Communication of Jealousy}

It is important to note the lack of responses to jealousy that reflected constructive communication. While participants provided many examples of destructive, avoidant, and rivalfocused responses, the findings reflected only one constructive communication example. There are some possible reasons for this finding that require further exploration.

There is a chance that self-reporting and self-selection bias influenced the data provided. Notably, outside of academia, the term 'jealousy’ has an almost exclusively dark-sided connotation (Degges-White, 2018). Therefore, when self-selecting to participate in this survey, potential participants may not have volunteered based on the assumption that they had not been the recipients of dark-sided jealousy expression. In fact, when asked if they thought the jealousy expressions of the particular partner on which they reported was average for a bisexual or pansexual person, some said no. For instance, one participant (woman, bisexual) reported: 
Not at all! I think he was a rare case. All of my romantic partners before/since have been no more or less jealous than average heterosexual couples. This particular guy, though, I think was just biphobic and extremely insecure

Similarly, another participant (woman, bisexual) shared, "I think my experience has been average because not all of my partners have acted the way this one did. Some have been very accepting and far from jealous." So while participants were able to recall destructive, avoidant, or rival-focused jealousy expressions, some explained that their responses were not reflective of all past relationships. However, even if they had experienced constructive jealousy expression, they may have made the decision not to participate if they could not think of any dark-sided jealousy expression experiences.

Previous studies also indicate that romantic couples who communicate their jealousy in constructive ways are less likely to experience dark-sided negative outcomes and are more likely to report being satisfied with their relationships despite the experience of jealousy (Andersen et al. 1995; Guerrero \& Andersen, 1998). Therefore, as there was a lack of constructive communication strategy examples in this study, it could be beneficial to the study of communication to specifically address this type of jealousy expression to better understand in what contexts, and with what identities, constructive communication is more or less likely to occur.

\section{Practical Implications}

The conclusions drawn from the data provide valuable information that can further the study of queer theory and jealousy expression. There are also several practical implications. Practical implications from this study include increasing partner awareness, addressing safety 
concerns for bisexual and pansexual individuals, and addressing stigma within the LGBTQIA+ community.

\section{Increasing Partner Awareness}

This research can help guide those who are romantic partners of bisexual or pansexual individuals. From this study, findings for RQ2 and RQ3 demonstrate how bisexual and pansexual individuals are aware of how their monosexist partners perceive their sexual orientation. Participants reported that their monosexist partners did not understand what being bisexual or pansexual actually meant, which partners demonstrated by their biphobic commentary and misplaced jealousy/jealousy expression. Therefore, if an individual is the romantic partner of a bisexual or pansexual individual, it could be helpful to garner awareness for one's own predisposed assumptions and jealousy expression approaches. Specifically, it could be helpful for monosexist partners to acknowledge/address their predisposed perception of untrustworthiness, and additionally enter the relationship aware of their gendered perception of threats/rivals because jealousy communication has the power to strengthen or harm a romantic relationship, depending on the type of communication utilized (Guerrero, 2014). Obtaining a more accurate understanding of what it means to be bisexual or pansexual could not only ease the mind of the monosexist partner, but also provide a safer and more understanding and accepting relationship space for the participant.

On a broader scale, this research could aid in the coaching of romantic partners. Specifically, if relationship coaches, family therapists, and other individuals in relational advicegiving professions have a better understanding of the unique dynamics within relationships involving one bisexual or pansexual person, there is more of a chance that the advice they give will be appropriate for the specific relationship. Interventions and professionals should teach that 
jealousy expression is not inherently harmful if handled in an appropriate manner (Andersen et al. 1995; Buss, 2018; Guerrero \& Andersen, 1998; Guerreros, 2014; Pines, 1992). Specifically, it could be beneficial for monosexist partners to learn how to apply constructive jealousy expression in their communication. Findings for RQ1 indicate a lack of constructive jealousy expression communication from monosexist partners in this study, yet participants clarified that they had experienced partners using constructive communication in the past. Guerrero et al. (1995) outline specific examples of constructive jealousy expression; given the benefits of constructive jealousy expression, it may be beneficial for relationship coaches to implement the utilization of this communication strategy with future clients/mentees.

\section{LGBTQIA+ Safety}

Scholars should further investigate the connection between jealousy expression and violence towards bisexual and pansexual individuals in romantic relationships. Jealousy and jealousy expression can illicit uncomfortable and even dangerous experiences. Previous research demonstrated that jealousy has been linked to violence in heterosexual relationships (Buss, 2018). With participants confessing verbal, physical, and psychologically violent experiences, this study demonstrates that bisexual and pansexual individuals are also victims/survivors of romantic partner violence. In short, bisexual and pansexual individuals do experience abusive jealousy expression from their monosexist partners.

Bisexual and pansexual individuals can use the findings of this study to better understand their partners' jealousy and jealousy expression. These data can help individuals proactively anticipate what their experience(s) with jealousy may be, understand that they may incur violence, and make decisions accordingly. As previously stated, between 2009 and 2013, a total of 433 homicides were committed where jealousy likely played a role (FBI, 2013). The findings 
suggest that bisexual and pansexual individuals are not immune from this violence. Being a literal life-and-death situation, the continued understanding of the relationship between queer theory and jealousy studies will guide future research and aid in the awareness of LGBTQIA+ lived experiences.

\section{Addressing Stigma in the LGBTQIA+ Community}

The ostracization of the bisexual and pansexual identity is also present within the queer community (Dilley, 1999). Bisexual and pansexual individuals have been made the "queer among queers, queer among straights, and just plain queer” (Ka'ahumanu \& Hutchins, 2015, p. 364). The findings from this study indicate that bisexual and pansexual individuals continue to endure stigma about their sexual orientations, even from their fellow LGBTQIA+ community members and romantic relationship partners. Although a majority of the partners in this study were not members of the LGBTQIA+ community, there were several partners who were members of the community who still stigmatized the bisexual and pansexual participants. For example, one participant (woman, bisexual) with an LGBTQIA+ partner shared that, "My partner definitely seemed more threatened around males because it seemed as though they didn't really take my sexuality seriously to the point where they didn't even consider females on the same level as a threat." In another participant's (woman, bisexual) experience with an LGBTQIA+ partner, she shared that, "I would not argue that my sexuality was explicitly used, but there was suspicion when hanging around with male platonic friends." In both examples, the participants reported experiencing judgement from romantic partners within the community. While there is not enough data to indicate trends within specific identities, responses like these imply that even when dating members of the community, bisexual and pansexual individuals can experience biphobic communication. This information can help young bisexual and pansexual 
individuals understand what kind of role jealousy may play in their romantic relationship, regardless of their partners' sexual orientation.

\section{Limitations and Future Directions}

The findings in this study must be interpreted considering some limitations that also contribute to possible future areas of research. The primary limitations for this study include the participant demographics and data collection structure.

\section{Participant Demographics}

First, it is important to address the participants' demographics. The researcher chose to focus on pansexual and bisexual individuals. However, given that the researcher did not include all non-monosexist sexual orientations (e.g. demisexual, queer), the research cannot be applied to all LGBTQIA+ members. Findings do indicate that gender identities play a role in jealousy expression. Therefore, future research should explore identities that, while not monosexist, are also not pansexual and bisexual.

Other participant demographics were not diverse. Specifically, 51 of the 62 of participants were white and 47 participants were female. These demographic traits are unsurprising as the researcher recruited from a medium-sized midwestern campus. This predominantly white and female participant pool means that the data cannot be interpreted as representative of the "normal" bisexual or pansexual experience. As one's identity influences jealousy (e.g., Sagarin et al., 2003; Sagarin, et al., 2012; Sheets \& Wolfe, 2001), and some participants mentioned that citizenship status, age, and religious affiliation influenced their

partners' jealousy expression, other demographic information should be considered in future research. 
Lastly, when examining the differences between partners who were men versus partners who were women, exemplars tended to focus on men as partners, which may appear to reflect the notion that men express more jealousy compared to women. However, more participants reflected on partners who were men $(n=44)$ compared to partners who were women $(n=16)$; thus it is important to continue this line of research, particularly exploring gender identity differences, to determine if this disproportionate amount of exemplars is a function of the sample or is telling us something about gender identity differences in the expression of jealousy in these relationship types.

\section{Data Collection Structure}

This study's second limitation is the data collection style. The researcher chose to utilize online surveys. While this choice resulted in a higher sample size, the researcher was limited in conclusions that could be made due to researcher being unable to ask follow-up questions. For instance, it is important to ask questions regarding violent jealousy expression strategies. Specifically, the researcher was unable to determine whether participants perceive their sexual orientation to be a direct factor in their partners' violent communication. Also, as some partners expressed that they could not "compete" with another gender identity, it will be important in the future to further explore what partners mean by different gender identities having "something to offer" that they do not. Finally, in future studies, with an interview-based data collection approach, researchers could explore how the Double Shot Hypothesis is represented in romantic relationships involving a bisexual or pansexual partner. Specifically, understanding motivation for one's feelings of jealousy could then inform this exploration of jealousy expression. 


\section{Conclusion}

In this study, the researcher established that jealousy expression is present in dyadic romantic relationships where one partner is bisexual or pansexual. While many questions remain unanswered, the findings indicate that bisexual and pansexual individuals experience partner jealousy expression in ways similar to the responses reflected in the CRJ scale and that bi- and pansexual orientations play a role in a monosexist partner's jealousy expression. 


\section{REFERENCES}

Andersen, P. A., Eloy, S. V., Guerrero, L. K., \& Spitzberg, B. H. (1995). Romantic jealousy and relational satisfaction: A look at the impact of jealousy experience and expression. Communication Reports, 8(2), 77-85.

https://doi.org/10.1080/08934219509367613

Barelds, D. P., \& Barelds-Dijkstra, P. (2007). Relations between different types of jealousy and self and partner perceptions of relationship quality. Clinical Psychology \& Psychotherapy: An International Journal of Theory \& Practice, 14(3), 176-188. https://doi.org/10.1002/cpp.532

Barta, W. D., \& Kiene, S. M. (2005). Motivations for infidelity in heterosexual dating couples: The roles of gender, personality differences, and sociosexual orientation. Journal of Social and Personal Relationships, 22(3), 339-360.

https://doi.org/10.1177/0265407505052440

Bevan, J. L. (2004). General partner and relational uncertainty as consequences of another person's jealousy expression. Western Journal of Communication, 68(2), 195-218. https://doi.org/10.1080/10570310409374796

Bevan, J. L. (2013). The communication of jealousy. Peter Lang.

Bevan, J. L., \& Lannutti, P. J. (2002). The experience and expression of romantic jealousy in same-sex and opposite-sex romantic relationships. Communication Research Reports, 19(3), 258-268. https://doi.org/10.1080/08824090209384854

Braun, V., \& Clarke, V. (2006). Using thematic analysis in psychology. Qualitative Research in Psychology, 3(2), 77-101. https://doi.org/10.1191/1478088706qp063oa 
Buss, D. M. (2018). Sexual and emotional infidelity: Evolved gender differences in jealousy prove robust and replicable. Perspectives on Psychological Science, 13(2), 155-160. https://doi.org/10.1177/1745691617698225

Buunk, B. P. (1997). Personality, birth order and attachment styles as related to various types of jealousy. Personality and Individual Differences, 23(6), 997-1006. https://doi.org/10.1016/S0191-8869(97)00136-0

Calafell, B. M., \& Eguchi, S. (2020). Are we queer yet? Queerness on the horizon in academia. In A. L. Johnson \& B. LeMaster (Eds.), Gender futurity, intersectional autoethnography: Embodied theorizing from the margins (pp. 69-84). Routledge.

Carpenter, C. J. (2012). Meta-analyses of sex differences in responses to sexual versus emotional infidelity: Men and women are more similar than different. Psychology of Women Quarterly, 36(1), 25-37. https://doi.org/10.1177/0361684311414537

Carson, C. L., \& Cupach, W. R. (2000). Fueling the flames of the green-eyed monster: The role of ruminative thought in reaction to romantic jealousy. Western Journal of Communication, 64(3), 308-329. https://doi.org/10.1080/10570310009374678

Carson, N. D., \& Johnson, R. E. (1985). Suicidal thoughts and problem-solving preparation among college students. Journal of College Student Personnel, 26, 484-487. https://psycnet.apa.org/record/1986-24755-001

Dainton, M. (2003). Equity and uncertainty in relational maintenance. Western Journal of Communication (includes Communication Reports), 67(2), 164-186. https://doi.org/10.1080/10570310309374765 
Dainton, M., \& Aylor, B. (2001). A relational uncertainty analysis of jealousy, trust, and maintenance in long-distance versus geographically close relationships. Communication Quarterly, 49(2), 172-188. https://doi.org/10.1080/01463370109385624

DeSteno, D. A., \& Salovey, P. (1996). Evolutionary origins of sex differences in jealousy? Questioning the "fitness" of the model. Psychological Science, 7(6), 367-372. https://doi.org/10.1111/j.1467-9280.1996.tb00391.x

Degges-White, S. (2018, Feb 20). What's Wrong With a Little Bit of Jealousy?. PsychologyToday. https://www.psychologytoday.com/us/blog/lifetimeconnections/201802/what-s-wrong-little-bit-jealousy

Dilley, P. (1999). Queer theory: Under construction. International Journal of Qualitative Studies in Education, 12(5), 457-472. https://doi.org/10.1080/095183999235890

Ding, J. Y., \& Rule, N. O. (2012). Gay, straight, or somewhere in between: Accuracy and bias in the perception of bisexual faces. Journal of Nonverbal Behavior, 36(2), 165-176. https://doi.org/10.1007/s10919-011-0129-y

Esterline, K. M., \& Galupo, M. P. (2013). "Drunken curiosity” and "gay chicken": Gender differences in same-sex performativity. Journal of Bisexuality, 13, 106-121. doi:10.1080/15299716.2013.755732

Federal Bureau of Investigation (FBI). (2013). Expanded homicide data table 12. Crime in the United States 2013. Retrieved from https://www.fbi.gov/about-us/cjis/ucr/crime-in-theu.s/2013/crime-in-the-u.s.-2013/offensesknown-to-law-enforcement/expandedhomicide/expanded_homicide_data_table_12_murder_circumstances_2009-2013.xls 
Fleischmann, A. A., Spitzberg, B. H., Andersen, P. A., \& Roesch, S. C. (2005). Tickling the monster: Jealousy induction in relationships. Journal of Social and Personal Relationships, 22(1), 49-73. https://doi.org/10.1177/0265407505049321

Gates, G. J. (2011, April). How Many People are Lesbian, Gay, Bisexual, and Transgender? UCLA School of Law, Williams Institute. https://williamsinstitute.law.ucla.edu/publications/how-many-people-lgbt/

Guerrero, L. K. (1998). Attachment-style differences in the experience and expression of romantic jealousy. Personal Relationships, 5(3), 273-291. https://doi.org/10.1111/j.14756811.1998.tb00172.x

Guerrero, L. K. (2014). Jealousy and relational satisfaction: Actor effects, partner effects, and the mediating role of destructive communicative responses to jealousy. Western Journal of Communication, 78(5), 586-611. https://doi.org/10.1080/10570314.2014.935468

Guerrero, L. K., \& Andersen, P. A. (1998). The dark side of jealously and envy: Desire, delusion, desperation, and destructive communication. Western Journal of Communication, 59(4), 270-304. https://doi.org/10.1080/10570319509374523

Guerrero, L. K., Andersen, P. A., Jorgensen, P. F., Spitzberg, B. H., \& Eloy, S. V. (1995). Coping with the green-eyed monster: Conceptualizing and measuring communicative responses to romantic jealousy. Western Journal of Communication, 59(4), 270-304. https://doi.org/10.1080/10570319509374523

Guerrero, L. K., Andersen, P. A., \& Spitzberg, B. H. (2003, July). Communicative responses to jealousy. Featured research presentation at the annual conference of the International Association for Relationship Research, Madison, WI. 
Guerrero, L. K., Hannawa, A. F., \& Babin, E. A. (2011). The communicative responses to jealousy scale: Revision, empirical validation, and associations with relational satisfaction. Communication Methods and Measures, 5(3), 223-249. https://doi.org/10.1080/19312458.2011.596993

Gustavson, M. (2009). Bisexuals in relationships: Uncoupling intimacy from gender ontology. Journal of Bisexuality, 9(3-4), 407-429. https://doi.org/10.1080/15299710903316653

Harris, C. R. (2002). Sexual and romantic jealousy in heterosexual and homosexual adults. Psychological Science, 13(1), 7-12. https://doi.org/10.1111/1467-9280.00402

Harris, C. R., \& Christenfeld, N. (1996). Gender, jealousy, and reason. Psychological Science, 7(6), 364-366. https://doi.org/10.1111/j.1467-9280.1996.tb00390.x

Henderson, L. (2001). Queer communication studies. Annals of the International Communication Association, 24(1), 465-484. https://doi.org/10.1080/23808985.2001.11678998

Johnson, E. P. (2001). "Quare” studies, or (almost) everything I know about queer studies I learned from my grandmother. Text and Performance Quarterly, 21(1), 1-25. https://doi.org/10.1080/10462930128119

Ka'ahumanu, L., \& Hutchins, L. (2015). Bi any other name: Bisexual people speak out. Riverdale Avenue Books LLC.

Kennedy-Lightsey, C., \& Booth-Butterfield, M. (2011). Responses to jealousy situations that evoke uncertainty in married and dating relationships. Communication Quarterly, 59(2), 255-275. https://doi.org/10.1080/01463373.2011.563443

Kulick, D. (2000). Gay and lesbian language. Annual Review of Anthropology, 29(1), 243-285. https://doi.org/10.1146/annurev.anthro.29.1.243 
MacDonald, Jr, A. P. (1981). Bisexuality: Some comments on research and theory. Journal of Homosexuality, 6(3), 21-36. https://doi.org/10.1300/J082v06n03_02

Madison, N. (2017). The bisexual seen: Countering media misrepresentation. Media Culture Journal, 20(4). https://doi.org/10.5204/mcj.1271

Manning, J., Asante, G., Huerta Moreno, L., Johnson, R., LeMaster, B., Li, Y., Rudnick, J., Stern, D., \& Young, S. (2020). Queering communication studies: A Journal of Applied Communication Research forum. Journal of Applied Communication Research, 48(4), 413-437. https://doi.org/10.1080/00909882.2020.1789197

Mathes, E. W. (1986). Jealousy and romantic love: A longitudinal study. Psychological Reports, 58(3), 885-886. https://doi.org/10.2466/pr0.1986.58.3.885

McNally, V. (2016, Sept. 22). 9 bisexual characters who defy all the evil cheating sex fiend stereotypes. Revelist. https://www.revelist.com/pop-culture/bisexual-pop-culturecharacters/4927

Obradors-Campos, M. (2011). Deconstructing biphobia. Journal of Bisexuality, 11(2-3), 207226. https://doi.org/10.1080/15299716.2011.571986

Pines, A. M. (1992). Romantic Jealousy: Understanding and conquering the shadow of love. St. Martin's Press

Rice, K. (2015). Pansexuality. The International Encyclopedia of Human Sexuality, 861-1042. https://doi.org/10.1002/9781118896877.wbiehs328

Rust, P. C. (1996). Managing multiple identities: Diversity among bisexual women and men. In B. A. Firestein (Ed.), Bisexuality: The psychology and politics of an invisible minority (p. 53-83). Sage Publications, Inc. 
Sagarin, B. J., Becker, D. V., Guadagno, R. E., Nicastle, L. D., \& Millevoi, A. (2003). Sex differences (and similarities) in jealousy: The moderating influence of infidelity experience and sexual orientation of the infidelity. Evolution and Human Behavior, 24(1), 17-23. https://doi.org/10.1016/S1090-5138(02)00106-X

Sagarin, B. J., Martin, A. L., Coutinho, S. A., Edlund, J. E., Patel, L., Skowronski, J. J., \& Zengel, B. (2012). Sex differences in jealousy: A meta-analytic examination. Evolution and Human Behavior, 33(6), 595-614. https://doi.org/10.1016/j.evolhumbehav.2012.02.006

Scherer, C. R., Akers, E. G., \& Kolbe, K. L. (2013). Bisexuals and the sex differences in jealousy hypothesis. Journal of Social and Personal Relationships, 30(8), 1064-1071. https://doi.org/10.1177/0265407513481446

Seidman, S. (1995). Deconstructing queer theory or the under-theorization of the social and the ethical. In L. Nicholson \& S. Seidman (Editors), Social postmodernism: Beyond identity politics (pp. 116-141). Cambridge University Press. doi:10.1017/CBO9780511520792.007

Sheets, V. L., \& Wolfe, M. D. (2001). Sexual jealousy in heterosexuals, lesbians, and gays. Sex Roles, 44(5-6), 255-276. https://doi.org/10.1023/A:1010996631863

Spalding, L. R., \& Peplau, L. A. (1997). The unfaithful lover: Heterosexuals’ perceptions of bisexuals and their relationships. Psychology of Women Quarterly, 21, 611-625. https://doi.org/10.1111/j.1471-6402.1997.tb00134.x

Thorne, L. (2013). "But I'm attracted to women”: Sexuality and sexual identity performance in interactional discourse among bisexual students. Journal of Language and Sexuality, 2(1), 70-100. https://doi.org/10.1075/jls.2.1.03tho 
Weinberg, M. S., Williams, C. J., \& Pryor, D. W. (1995). Dual attraction: Understanding bisexuality. Oxford University Press.

White, G. L., \& Mullen, P. E. (1989). Jealousy: Theory, research, and clinical strategies. Guilford Press.

Yost, M. R., \& Thomas, G. D. (2012). Gender and binegativity: Men's and women's attitudes toward male and female bisexuals. Archives of Sexual Behavior, 41, 691-702. https://doi.org/10.1007/s10508-011-9767-8 


\section{APPENDIX A: RESEARCH BOARD RECRUITMENT}

You qualify to participate in the following study if:

- You identify as bisexual or pansexual.

- You have been in a romantic relationship where your partner knew about your sexual orientation, was only sexually and romantically attracted to a single gender identity (e.g. lesbian, gay, straight), and expressed feelings of romantic jealousy.

- You are at least 18 years old.

If you qualify to participate in this study, please fill out the following open-ended questionnaire. I will also change your name on the final thesis. 


\section{APPENDIX B: EMAIL RECRUITMENT}

Dear

I am a graduate student in the School of Communication at Illinois State University and am conducting a research study for my Master's thesis to better understand how individuals who identify as bisexual or pansexual have had romantic jealousy expressed to them. If...

- You identify as bisexual or pansexual.

- You have been in a romantic relationship where your partner knew about your sexual orientation, was only sexually and romantically attracted to a single gender identity (e.g. lesbian, gay, straight), and expressed feelings of romantic jealousy.

- You are at least 18 years old.

Then I request your participation.

You are invited to participate in an open-ended questionnaire study regarding the communication from your former partner that displayed romantic jealousy. The questionnaire will take approximately 30 minutes. It will be confidential (I will not share your identity with others) and I will change your name on the final paper for this project. Your participation will be completely voluntary. You may decide not to answer any question, and you can stop the questionnaire at any time.

Please direct any questions and/or comments to my thesis advisor, Dr. Aimee Miller-Ott (aeott@ilstu.edu), or to me.

If you would like to participate, please contact me at the e-mail address below.

Sincerely,

Emily (MJ) Mason

Graduate Student, School of Communication

Illinois State University

Ejmaso2

@ilstu.edu 


\section{APPENDIX C: SOCIAL MENDIA RECRUITMENT POST}

Hello! I am currently conducting research for my Master's Thesis on the relationship between jealousy expression and the bisexual and pansexual community. I am conducting this research under the supervision of Dr. Miller-Ott in the School of Communication at Illinois State University. If you have a moment to spare, I would appreciate any and all volunteers willing to dedicate roughly 20 minutes of their day to answering an open-ended questionnaire regarding their lived experiences.

To participate in this study, you must:

- Identify as bisexual or pansexual.

- Have been in a romantic relationship where your partner knew about your sexual orientation, was only sexually and romantically attracted to a single gender identity (e.g. lesbian, gay, straight), and expressed feelings of romantic jealousy.

- Be least 18 years old.

The study should take about 20-30 minutes. Responses will be anonymous. Please click the link below to complete the survey. 


\section{APPENDIX D: OPEN ENDED QUESTIONNAIRE}

Thank you for agreeing to participate in my study on romantic jealousy expression. You will answer a series of open-ended questions regarding you and your former partner's communication specifically focusing on moments where your partner displayed feelings of romantic jealousy. If you have experienced multiple partners like this, please just choose one to answer the whole survey about.

1. What is your age?

2. What is your sex?
a. Male
b. Female
c. Other

3. What is your gender?
a. Man
b. Non-binary
c. Transgender Man
d. Transgender Woman
e. Woman
f. Other

4. What is your sexuality?

a. Bisexual

b. Pansexual

c. Other - Unfortunately, if you do not identify as Bisexual or Pansexual, you do not qualify to be a participant in this study.

5. What is your ethnicity?
a. Asian
b. Black
c. Hispanic
d. Native American
e. White
f. Other

Next, I would like to ask you some background information about your former partner:

6. What was your partner's sex?
a. Male
b. Female
c. Other

7. What was your partner's gender?
a. Man
b. Non-binary
c. Transgender Man
d. Transgender Woman
e. Woman
f. Other

8. What was your partner's sexuality?

a. Asexual 
b. Bisexual

c. Gay

d. Heterosexual/ Straight

e. Lesbian

f. Pansexual

g. Other

9. What was your partner's ethnicity?

a. Asian

b. Black

c. Hispanic

d. Native American

e. White

f. Other

10. What was the nature of your romantic relationship with this person?

a. Casually dating

b. Seriously dating

c. Engaged

d. Married

11. How long was the romantic relationship?

12. What was your age when you established the romantic relationship?

13. What was your partner's age when you established the romantic relationship?

Next, I would like you to answer questions giving some background information about your former partner's expression(s) of jealousy:

14. When your partner expressed jealousy to you, how did they do it?

15. When your partner expressed jealousy, what are things they would say?

16. When your partner expressed jealousy, what are things they would do?

17. On a scale from 1 to 5 (one being never, five being frequently) how often did your partner express jealousy by...

a. Having a conversation about it

b. Flirting with another individual

c. Threatening to end your relationship

d. Stalking/ spying on you

e. Become confrontational with the person they were jealous of

f. Denying that they were feeling jealous

g. Cheating on you with another individual

h. Making violent threats towards you

i. Avoiding you

To wrap up, I would like to ask you some general questions about your experience with romantic jealousy expression:

18. Did you ever feel that your sexual orientation was utilized as justification for feeling jealous and how they expressed it? If so, how? 
19. Did your former partner ever seem to feel threatened/exhibit jealousy regarding any specific sex/gender threat (e.g. your partner get more threatened around males than female threats)? How could you tell?

20. Are there any specific contexts in your or your partner's behavior that might make your partner's jealousy (un)warranted?

21 . Is there anything else you would like to share concerning your former partner?

22. Would you consider your experience with jealousy (as a bisexual/pansexual individual) normal compared to others? Why or why not?

23. What suggestions would you have for someone who is in a romantic relationship with someone who demonstrates romantic jealousy? 


\section{APPENDIX E: INFORMED CONSENT}

\section{Dear participant,}

I am a graduate student under the direction of Professor Aimee Miller-Ott in the School of Communication at Illinois State University. As part of the program requirement, I am conducting my thesis to better understand jealousy in romantic relationships in which one partner identifies as bisexual or pansexual.

Your participation will involve responding to an open-ended questionnaire about communication with a former romantic partner. The questionnaire will be distributed digitally and will take approximately 20 minutes. You may participate in this study if...

- You identify as bisexual or pansexual.

- You have been in a romantic relationship where your partner knew about your sexual orientation, was only sexually and romantically attracted to a single gender identity (e.g. lesbian, gay, straight), and expressed feelings of romantic jealousy.

- You are at least 18 years old.

Additionally, the relationship must be a past relationship, not a current relationship.

Your participation in this study is voluntary. You may refuse to answer any question. You may skip or refuse to answer questions if you feel uncomfortable, and if you choose not to participate or to withdraw from the study at any time, there will be no penalty. Your responses are anonymous. Your responses will be joined with those of other participants to develop themes for research presentation at conference or in publication.

As a participant, you may experience discomfort when talking about personal experiences. Participants may experience psychological or emotional pain. Participants who are distressed may contact Student Counseling Services at (309) 438-3655. Participants who are not ISU students may call the Substance Abuse and Mental Health Services Administration (SAMHSA) at 1-800-662-HELP (4357).

If you have any questions about your rights as a subject/participant in this research, or if you feel you have been placed at risk, you can contact the Research Ethics \& Compliance Office at Illinois State University at (309) 438-5527.

Sincerely,

Emily (MJ) Mason, Graduate Student, School of Communication

Illinois State University

Ejmaso2@ilstu.edu 